\title{
Effects of Tropical Cyclones on ENSO
}

\author{
TAO LIAN AND JUN YING \\ State Key Laboratory of Satellite Ocean Environment Dynamics, Second Institute of Oceanography, Ministry of \\ Natural Resources, Hangzhou, China \\ HONG-Li REN \\ Laboratory for Climate Studies, National Climate Center, China Meteorological Administration, Beijing, China \\ Chan Zhang, Ting LiU, And XiaO-Xiao Tan \\ State Key Laboratory of Satellite Ocean Environment Dynamics, Second Institute of Oceanography, Ministry of \\ Natural Resources, Hangzhou, China
}

(Manuscript received 5 December 2018, in final form 28 June 2019)

\begin{abstract}
Numerous studies have investigated the role of El Niño-Southern Oscillation (ENSO) in modulating the activity of tropical cyclones (TCs) in the western Pacific on interannual time scales, but the effects of TCs on ENSO are less discussed. Some studies have found that TCs sharply increase surface westerly anomalies over the equatorial western-central Pacific and maintain them there for a few days. Given the strong influence of equatorial surface westerly wind bursts on ENSO, as confirmed by much recent literature, the effects of TCs on ENSO may be much greater than previously expected. Using recently released observations and reanalysis datasets, it is found that the majority of near-equatorial TCs (simply TCs hereafter) are associated with strong westerly anomalies at the equator, and the number and longitude of TCs are significantly correlated with ENSO strength. When TC-related wind stresses are added into an intermediate coupled model, the simulated ENSO becomes more irregular, and both ENSO magnitude and skewness approach those of observations, as compared with simulations without TCs. Adding TCs into the model system does not break the linkage between the heat content anomaly and subsequent ENSO event in the model, which manifest the classic recharge-discharge ENSO dynamics. However, the influence of TCs on ENSO is so strong that ENSO magnitude and sometimes its final state-that is, either El Niño or La Niña-largely depend on the number and timing of TCs during the event year. Our findings suggest that TCs play a prominent role in ENSO dynamics, and their effects must be considered in ENSO forecast models.
\end{abstract}

\section{Introduction}

As the most energetic short-term climate variability on Earth, El Niño-Southern Oscillation (ENSO) significantly influences the global climate system (Philander 1990). Numerous studies have investigated the effects of ENSO on the activity of tropical cyclones (TCs) in the western Pacific, one of the most devastating weather phenomena in the western Pacific and Maritime Continent, on interannual time scales [see the review by Camargo et al. (2010)]. It is now widely accepted by the climate community that ENSO is a major factor in modulating the interannual variability of the frequency,

\footnotetext{
Corresponding author: Tao Lian, liantao@sio.org.cn
}

intensity, genesis location, and lifetime of TCs (Lander 1994; Chan 2000; Wang and Chan 2002; Chand et al. 2013; Sobel et al. 2016; and many others). For example, the genesis location of TCs is more eastward and equatorward in El Niño years than in La Niña years, given the higher relative humidity and weaker vertical wind shear over the tropical western-central Pacific associated with the warm sea surface temperature (SST) and weakened trade winds over the equatorial Pacific in El Niño years (Wang and Chan 2002; Chand et al. 2013). The eastward movement of TC genesis locations also indicates a longer lifetime for TCs in El Niño years than in La Niña years (Chan 2005). The number of TCs, and particularly the number of intense TCs, increases during strong El Niño years (Wang and Chan 2002; Camargo and Sobel 2005). 

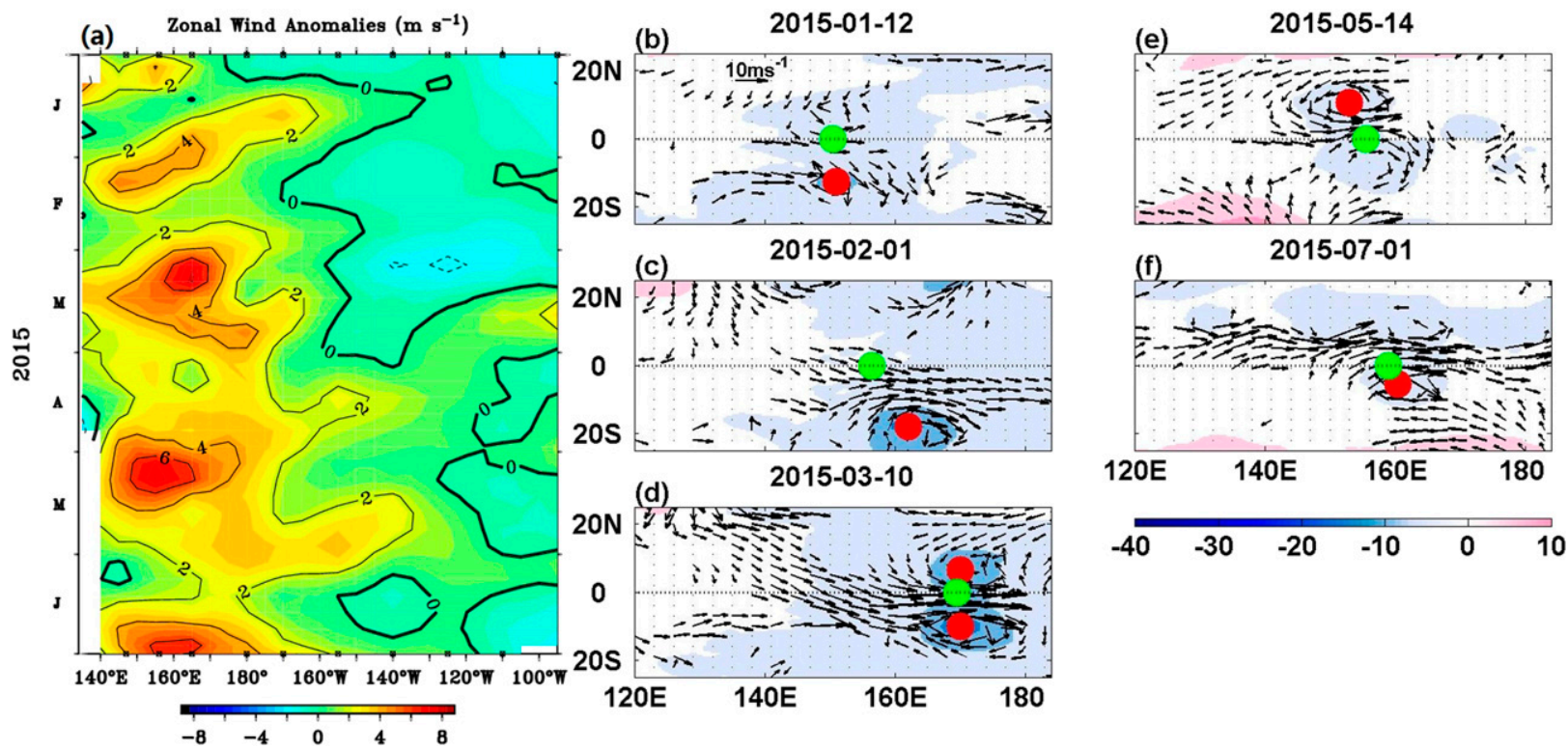

FIG. 1. (a) Evolution of zonal wind anomalies within $2^{\circ} \mathrm{S}-2^{\circ} \mathrm{N}$ in the first half of 2015 from TAO/TRITON observations provided by the TAO Project Office of PMEL, and (b)-(f) snapshots of sea level pressure anomalies (color; hPa) and surface wind anomalies (vectors; $\mathrm{m} \mathrm{s}^{-1}$ ) from daily ERA-Interim reanalysis data on five selected days in which the equatorial westerly anomalies in (a) reach maxima, with a resolution of $0.5^{\circ} \times 0.5^{\circ}$. Green and red dots in (b)-(f) indicate the positions of the maximum westerly anomalies and TCs, respectively. The TC position is from the IBTrACS dataset.

Because of these strong ENSO-related modulations of TC activity on interannual time scales, the accumulated cyclone energy (ACE) of TCs, an index of TC activity, is significantly and positively correlated with ENSO indices (Camargo and Sobel 2005).

The robust dependence of interannual TC activity on ENSO led to the proposal of a hybrid dynamicalstatistical approach for predicting seasonal TC activity (Kim et al. 2012; Li et al. 2013). In this approach, a coupled general circulation model (GCM) is first used to forecast the ENSO state in the coming year. Then, TC activities such as the annual frequency and ACE in the following TC seasons are predicted by regressing them over various ENSO indices. Although steady progress has been made in the design and improvement of the pure dynamical TC forecast model in recent decades [see the review by Camargo and Wing (2016)], the hybrid TC forecast model was found to have better (or at least competitive) skill in predicting seasonal TC activity than the pure dynamical model (Wang et al. 2009; Vecchi et al. 2011; Kim et al. 2013).

The hybrid TC forecast model has a basic assumption that the TCs place very weak influence on the coming ENSO event, which is perhaps not true. Pioneering work from Camargo and Sobel (2005) and Sobel and Camargo (2005) showed that TCs can greatly influence the largescale environment of the tropical Pacific, including the sharp increase of surface westerly anomalies over the equatorial western-central Pacific during TCs, and the warming SST anomalies in the centraleastern equatorial Pacific a few days after TCs occur. In particular, they pointed out that the ACE index of summer and autumn TCs significantly leads ENSO indicesby about six months-rather than lagging or co-occurring with ENSO indices. A series of recent studies confirmed that strong burst-like westerly anomalies over the western-central equatorial Pacific, often referred to as westerly wind bursts (WWBs), play a key role in ENSO dynamics (McPhaden 1999; Vecchi and Harrison 2000; Lengaigne et al. 2004; Lian et al. 2014; Chen et al. 2015; Levine et al. 2016; L. Chen et al. 2016; Chen et al. 2017; Gao and Zhang 2017; Wu et al. 2018) and prediction (Menkes et al. 2014; Hu and Fedorov 2016; Chiodi and Harrison 2017). In addition, it has been found that the majority of WWBs are associated with TCs (Keen 1982; Harrison and Giese 1991; Hartten 1996; Lian et al. 2018). For example, Fig. 1 presents the evolution of surface wind anomalies in the first half of 2015. All five strong WWBs, which have been alleged to have played a fundamental role in the genesis of the 2015-16 super El Niño (Hu and Fedorov 2016; Lian et al. 2017; Zhang and Gao 2016, 2017; Chen et al.2017), were accompanied by one or more TCs. These findings implied that TCs could influence ENSO evolution via the related large-scale surface wind anomalies, and the effects of TCs on ENSO excitation might be much greater than previously thought. 
Although the results of Camargo and Sobel (2005) and Sobel and Camargo (2005) are enlightening, to our knowledge a detailed analysis of the effects of TCs on ENSO dynamics has not been reported since these two pioneering papers. Some interesting and important questions remain unanswered. For instance, how long and to what extent can TCs affect an ENSO event? How can TC-related ENSO dynamics be understood in the context of the classic recharge-discharge ENSO theory (Jin 1997)? Can the number and timing of TCs affect ENSO prediction? In this study, the effects of TC-related large-scale surface wind anomalies on ENSO dynamics and prediction uncertainty are investigated using recently released observations and reanalysis data together with an intermediate coupled model. The rest of the manuscript is arranged as follows. The data, model, and methods used are introduced in section 2. Section 3 explores the statistical relationship between TCs and ENSO in observations. The influence of TCs on ENSO dynamics is explored using a set of model experiments in section 4. In section 5, we investigate the uncertainty in ENSO prediction associated with the TCs in the model, followed by a sensitivity analysis of our findings in section 6. A summary and discussion are given in section 7.

\section{Data, model, and method}

The datasets used here include the monthly SST from the Extended Reconstructed SST version 3 (ERSST3) for the period 1961-2015 with a spatial resolution of $2.0^{\circ} \times 1.0^{\circ}$ (Smith et al. 2008), the TC position since 1961 from the International Best Track Archive for Climate Stewardship (IBTrACS; Knapp et al. 2010), and the $10-\mathrm{m}$ wind and sea level pressure from the European Centre for Medium-Range Weather Forecasts (ECMWF) daily ERA-Interim reanalysis from 1979 to 2015 with a spatial resolution of $0.5^{\circ} \times 0.5^{\circ}$ (Dee et al. 2011). The analysis domain is set to the western-central tropical Pacific $\left(30^{\circ} \mathrm{S}-30^{\circ} \mathrm{N}, 110^{\circ} \mathrm{E}-160^{\circ} \mathrm{W}\right)$, and the anomaly is defined as the departure from the climatological seasonal cycle. The Niño-3 index, which is defined as the regionally averaged SST anomaly within the Niño-3 region $\left(150^{\circ}-90^{\circ} \mathrm{W}, 5^{\circ} \mathrm{S}-5^{\circ} \mathrm{N}\right)$, and its temporal average over the DJF season, referred to as Niño-3(DJF), are used to characterize ENSO in the present study. Following the ENSO definition of the National Oceanic and Atmospheric Administration (NOAA; http://origin.cpc. ncep.noaa.gov/products/analysis_monitoring/ensostuff/ ONI_v5.php), El Niño (La Niña) in both observations and model experiments is defined as an event such that the 3-month running mean of the Niño-3 index is greater (smaller) than $1(-1)$ standard deviation
(STD) of the Niño-3 index for at least 5 successive months.

The model used here is an intermediate oceanatmosphere coupled model (Zebiak and Cane 1987). This model covers the tropical Pacific basin $\left(100^{\circ} \mathrm{E}-\right.$ $\left.80^{\circ} \mathrm{W}, 30^{\circ} \mathrm{S}-30^{\circ} \mathrm{N}\right)$ with a resolution of $5.265^{\circ} \times 2.0^{\circ}$ and a time step of 10 days. The ocean component consists of a 50-m-deep mixed layer and a motionless subsurface layer, and the atmospheric component is a Gill-type steady-state linear model (Gill 1980). The ocean is forced by the surface wind stress as a function of surface wind from the atmospheric component, and the atmosphere is forced by sea surface heating, which is parameterized by SST. Although the model structure is simple, it captures basic ENSO dynamics, and has been the primary tool used by numerous investigators to understand ENSO dynamics and test ENSO predictability since its release in the early 1980s. Details of the model settings, validation, and performance can be found in Zebiak and Cane (1987).

To explore the effect of TCs on ENSO dynamics, we design a set of model experiments. The first experiment is identical to the default setting of the original model of Zebiak and Cane (1987), and is hereafter referred to as the $\mathrm{ZC}$ run. As will be seen in section 4 , adding TCs in model could sharply increase ENSO strength. To make the simulated ENSO strength in a realistic range, we set up the second experiment in which the drag coefficient $C_{d}$ is reduced from $2.56 \times 10^{-3}$ to $2.20 \times 10^{-3}$, and is referred to as the Ctrl run. We note that $C_{d}$ varies over a wide range (cf. Fig. 1 in Hsu et al. 2017), and the sensitivity of our results to $C_{d}$ is discussed in section 6 . The third experiment is an ocean model run in which the oceanic component of the $\mathrm{ZC}$ model is forced by a set of multiplicative TC-related wind stresses. This experiment is referred to as the TC-Alone run. The timing of each TC is purely random, but the number of TC days depends on the ENSO state. The scheme of TC parameterization and the structure of TC-related largescale wind stresses are given in section 3 . In the fourth experiment, the TC-related wind stresses are added to the modeled wind stress field. This experiment is referred to as the TC-Full run.

In the TC-Alone and TC-Full experiments, the latitude of TCs is fixed at $10^{\circ} \mathrm{N}$, and the radius of TCs is set at $13.0^{\circ}$ so that TC-related large-scale wind stresses can reach the equator. In addition, the wind stresses near the inner band of the TC and around the TC boundary are set as having the same magnitude of $0.2 \mathrm{Nm}^{-2}$ (details will be given in section 3 ). However, surface wind speeds near the inner band of the TC are much greater than at the TC boundary in the real world (Knaff et al. 2014; Chavas et al. 2016), and the number 
TABLE 1. Summary of model experiments used in this study.

\begin{tabular}{ll}
\hline \multicolumn{1}{c}{ Name } & \multicolumn{1}{c}{ Description } \\
\hline ZC run & Coupled run with model settings identical to those of Zebiak and Cane (1987) \\
Ctrl run & As for the ZC run, except for a smaller drag coefficient of $2.20 \times 10^{-3}$ \\
TC-Alone run & Ocean model run forced by TC-related wind stresses \\
TC-Full run & Coupled run with TC-related wind stresses added to the model wind stress field \\
Small-TC run & The same as the TC-Full run, except the TC radius is reduced from $13^{\circ}$ to $5^{\circ}$. \\
Small- and Strong-TC run & The same as Small-TC run, except the TC magnitude is increased from 0.2 to $0.3 \mathrm{~N} \mathrm{~m}^{-2}$. \\
Off-Eq-TC run & The same as the TC-Full run, except the latitude of TC is moved from $10^{\circ}$ to $20^{\circ} \mathrm{N}$. \\
Ensemble-TC-forecast run & A 100-member ensemble retrospective prediction of the TC-Full run with \\
& multiplicative TC-related wind stresses \\
\hline
\end{tabular}

of TCs in subtropical areas is greater than that in the tropical regions. An interesting question is whether the strong off-equatorial wind stresses near the inner band of TCs and the off-equatorial TC-related wind stress play a role in ENSO. To this end, we design three more experiments. The model settings used in the three experiments are identical to those of the TC-Full run except for the radius, latitude, and strength of TCs in the model. In the Small-TC run experiment, we shrink the radius of TCs from $13^{\circ}$ to $5^{\circ}$. In the Small- and Strong-TC run, we set the radius of TCs to $5^{\circ}$ with an increased magnitude of $0.3 \mathrm{~N} \mathrm{~m}^{-2}$. In the Off-Eq-TC run, the latitude of the TCs is moved northward to $20^{\circ} \mathrm{N}$.

For each model experiment mentioned above, the model is initiated with 4-month westerly wind anomalies over the equatorial western Pacific (Zebiak and Cane 1987) and integrated for 200 years. The TC-related wind stresses are added to the model beginning in year 11.

To investigate the effect of TCs on ENSO prediction and associated uncertainty, we take the SST anomaly from the TC-Full run as the predictand, and predict it by a 100 -member ensemble. For each ensemble member, the TC parameterization scheme is the same as that used in the TC-Full run. Because whether there is a TC at each step in each ensemble member is controlled by a random number (details will be given in section 3), the number and timing of TCs added to the model differ among the members. This ENSO prediction experiment is referred to as the Ensemble-TC-forecast run. For each member, a total of 1080 forecasts were conducted, each for a duration of 24 months. The forecasts were started at 1-month intervals from January of year 11 to December of year 100. Table 1 presents a brief summary of model experiments.

To explore ENSO dynamics in the model experiment, we analyze the heat budget of SST tendency, which is calculated as (Zebiak and Cane 1987):

$$
\begin{aligned}
\frac{\partial T}{\partial t}= & -u^{\prime} \frac{\partial \bar{T}}{\partial x}-\bar{u} \frac{\partial T^{\prime}}{\partial x}-u^{\prime} \frac{\partial T^{\prime}}{\partial x}-v^{\prime} \frac{\partial \bar{T}}{\partial y}-\bar{v} \frac{\partial T^{\prime}}{\partial y}-v^{\prime} \frac{\partial T^{\prime}}{\partial y} \\
& -\left[M\left(\bar{w}+w^{\prime}\right)-M(\bar{w})\right] \frac{\partial \bar{T}}{\partial z}-M\left(\bar{w}+w^{\prime}\right) \frac{\partial T^{\prime}}{\partial z}-\alpha T
\end{aligned}
$$

where $T, u, v$, and $w$ denote the average ocean temperature, zonal velocity, meridional velocity, and vertical velocity of ocean current in the upper $50 \mathrm{~m}$, respectively, and $\alpha T$ denotes the thermal damping. The primes and overbars denote anomalous and climatological seasonal mean values, respectively. The function $M(x)$ evaluates to $x$ when $x$ is greater than 0 , and to 0 otherwise. Following Jin et al. (2006) and Guan and McPhaden (2016), the heat budget is reformulated as

$$
\begin{aligned}
\frac{\partial T}{\partial t}= & -\left[M\left(\bar{w}+w^{\prime}\right)-M\left(w^{\prime}\right)\right] \frac{\partial T^{\prime}}{\partial z} \\
& -\left[M\left(\bar{w}+w^{\prime}\right)-M(\bar{w})\right] \frac{\partial \bar{T}}{\partial z}-u^{\prime} \frac{\partial \bar{T}}{\partial x}-v^{\prime} \frac{\partial \bar{T}}{\partial y} \\
& -\bar{u} \frac{\partial T^{\prime}}{\partial x}-\bar{v} \frac{\partial T^{\prime}}{\partial y}-\alpha T-\left[u^{\prime} \frac{\partial T^{\prime}}{\partial x}+v^{\prime} \frac{\partial T^{\prime}}{\partial y}+M\left(w^{\prime}\right) \frac{\partial T^{\prime}}{\partial z}\right]
\end{aligned}
$$

The first term denotes the thermocline feedback (TCF). The second term denotes the Ekman feedback (EKF). The third and fourth terms are the zonal advection feedback (ZAF) and the meridional advection feedback (MAF), respectively. The fifth and sixth terms denote the mean zonal advection feedback (MZAF) and the mean meridional advection feedback (MMAF), respectively. The seventh term is the thermal damping (TD), and the last term is the nonlinear dynamical heating (NDH). As shown by Jin et al. (2006) and Ren and Jin (2013), the TCF, EKF, and ZAF terms are the three major contributors to ENSO growth. 
The STD and skewness are used to quantitatively assess the effects of TCs on modeled ENSO in this study. The former follows ENSO strength, whereas the latter follows the degree of ENSO nonlinearity. To measure the uncertainty in ENSO predictions caused by multiplicative TCs, the spread of the forecasted index (e.g., Niño-3 index), which is defined as the difference between the maxima and minima among the ensemble members, is also employed. Note that the STD of the difference between predictand and forecast is generally used to measure the overall uncertainty of the prediction system (Tang et al. 2014). However, as here we are interested in whether TCs can lead to extreme El Niño events, the spread was used in the assessment.

\section{Diagnosing statistics between TCs and ENSO}

To characterize TCs that may play a role in ENSO dynamics, Fig. 2 presents the number of TC days (Fig. 2a) and the number of TC days that are associated with strong equatorial $\left(5^{\circ} \mathrm{S}-5^{\circ} \mathrm{N}\right)$ westerly anomalies at the same longitude as the TCs (Fig. 2b) as a function of latitudinal distance from the equator. Lian et al. (2018) showed that TCs identified from ERA-Interim are highly similar with those from IBTrACS in their frequency, spatial distribution, seasonality, etc. We thus use the TC positions from IBTrACS to diagnose the large-scale surface wind associated with TCs using ERA-Interim reanalysis. The strong westerly anomalies refer to anomalies greater than $3 \mathrm{~m} \mathrm{~s}^{-1}$, which is sufficient to reverse the climatological trade winds in the western-central equatorial Pacific and thus contribute to El Niño growth (Philander 1981). In addition, the longitude of surface wind from reanalysis and longitude of TC from IBTrACS is regarded to be the same if their difference is within the resolution of the reanalysis $\left(0.5^{\circ}\right.$ in this study).

As seen in Figs. 2a and 2b, while the number of TC days peaks $\sim 15^{\circ}$ from the equator, TCs that co-occur with strong equatorial westerly anomalies are generally found $\sim 12^{\circ}$ from the equator. In fact, nearly half of the TCs that occurred between $12^{\circ} \mathrm{S}$ and $12^{\circ} \mathrm{N}$ were associated with strong equatorial westerly anomalies (Fig. 2c). Figure $2 \mathrm{~d}$ shows the percentage of TC days with equatorial westerly anomalies at the same longitude as the TC that were greater than those on the five previous days, as a function of latitudinal distance from the equator. It is evident that about $50 \%$ of the TCs between $12^{\circ} \mathrm{S}$ and $12^{\circ} \mathrm{N}$ have the potential to increase equatorial westerly anomalies at the equator, suggesting that these near-equatorial TCs lead to rather than co-occur with strong westerly anomalies over the western-central equatorial Pacific.
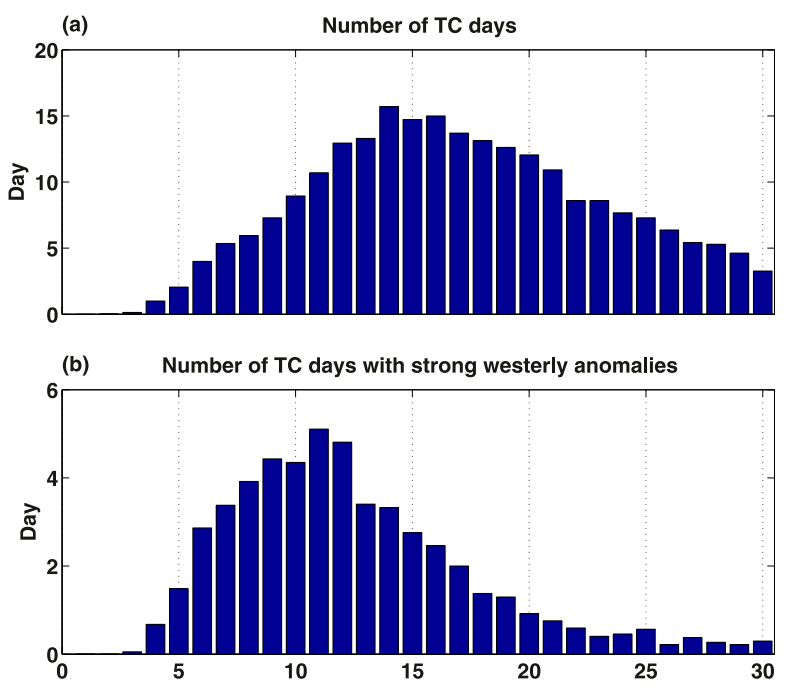

(c) Percentage of TC days with strong westerly anomalies

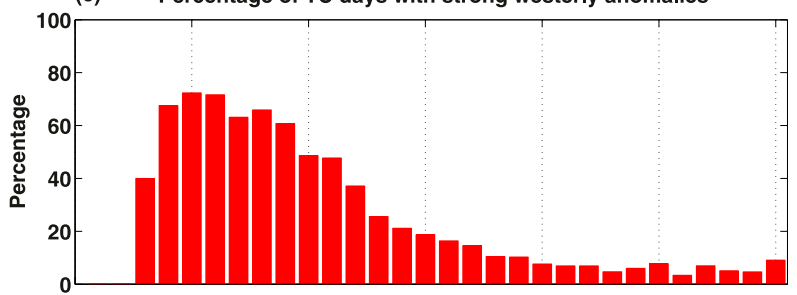

(d) Percentage of TC days with increased westerly anomalies

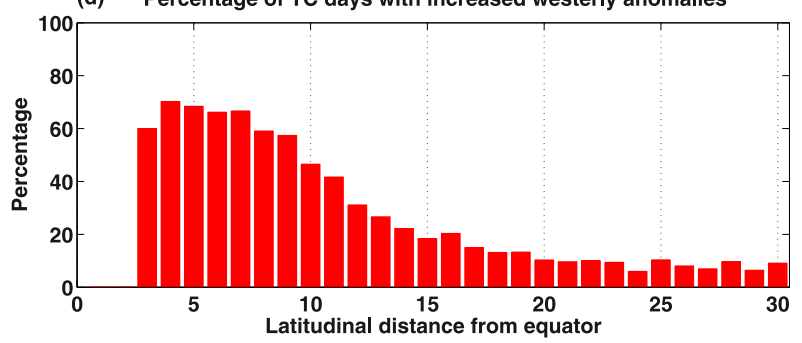

FIG. 2. (a) Annual-integrated number of TC days, (b) TC days with strong equatorial $\left(5^{\circ} \mathrm{S}-5^{\circ} \mathrm{N}\right)$ westerly anomalies at the longitude of the TCs, (c) percentage of TC days with strong equatorial westerly anomalies, and (d) percentage of TC days with equatorial westerly anomalies at the longitude of the TC greater than those on the five previous days as a function of latitudinal distance from the equator $\left(^{\circ}\right)$. TC data are from IBTrACS, and wind data are from ERA-Interim.

Figure 3 reduplicates Fig. 2 but for TCs in the western North Pacific (WNP) and the western South Pacific (WSP) during boreal summer-autumn (May-October) and winter-spring (November-April). Although the latitudinal distribution of the number of TC days is different for TCs in different hemispheres and seasons (Fig. 3a), about $50 \%$ of TC days within $12^{\circ}$ in latitude from the equator are coincident with strong equatorial westerly anomalies, regardless of hemisphere and season (Figs. 3c,d). We therefore focus on the relationship between ENSO and TCs that occur between $12^{\circ} \mathrm{S}$ and 

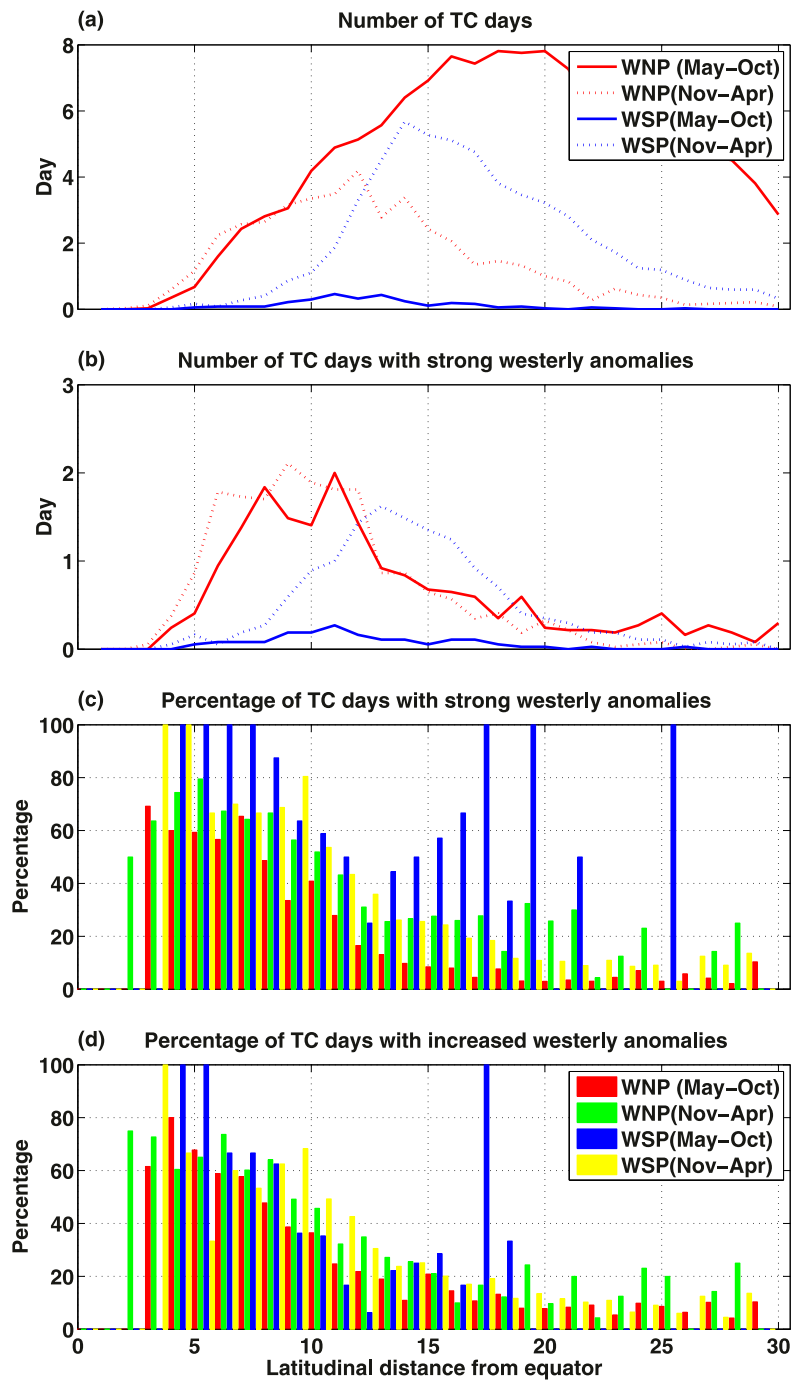

FIG. 3. (a) Seasonal-integrated number of TC days, (b) TC days with strong equatorial $\left(5^{\circ} \mathrm{S}-5^{\circ} \mathrm{N}\right)$ westerly anomalies at the longitude of the TCs, and the percentage of TC days with (c) strong and (d) increased equatorial westerly anomalies at the TC longitude as a function of latitudinal distance of the TC from the equator $\left(^{\circ}\right)$. In (a) and (b), red and blue lines denote TCs in the western North Pacific (WNP) and western South Pacific (WSP), respectively. Solid and dotted lines denote TCs in boreal summer-autumn (May-October) and boreal winter-spring (November-April), respectively.

$12^{\circ} \mathrm{N}$; these TCs are referred to as near-equatorial TCs, but we will simply call them TCs for short. It is worth noting that the number of TC days within $0^{\circ}-12^{\circ} \mathrm{N}$ is much greater than that within $0^{\circ}-12^{\circ} \mathrm{S}$ (Fig. 3b), indicating that the near-equatorial TCs that are associated with strong equatorial westerlies originate mainly in the western North Pacific.

Figure 4 presents the scatterplot of the annually integrated number of TC days (Fig. 4a), annual-average longitude (Fig. 4b), and annual-average latitudinal distance from the equator (Fig. 4c) of TCs against the Niño3(DJF) index. As confirmed by several previous studies (e.g., Wang and Chan 2002), the mean position of TCs is more eastward and equatorward in El Niño years than in La Niña years. To get the parameterization of TCs as a function of the Niño-3 index used in our model experiment, Fig. 5 further shows the scatterplot of the monthly integrated number of TC days (Fig. 5a), monthly average longitude (Fig. 5b), and monthly average latitudinal distance from the equator (Fig. 5c) of TCs against the Niño-3 index. It is clear that even for these monthly integrated/average values, the number of TC days and longitude of TCs are significantly correlated with ENSO. The average number of TC days is 4.42 days per month, and the mean longitude of TCs is $143.96^{\circ} \mathrm{E}$. For a $1^{\circ} \mathrm{C}$ increase in the Niño-3 index, the number of TC days increases by 1.02 days per month and moves eastward by $7.5^{\circ}$ (Figs. 5a,b). The mean latitudinal distance of TCs from the equator is $9.55^{\circ}$ (Fig. 5c). Note that unlike what we found in Fig. 4c, the monthly average latitudinal position of TCs is not significantly related to the monthly average Niño-3 index (Fig. 5c). Other effects such as the $\mathrm{MJO}$ and Asian/Australian monsoon might play the major role in determining the latitude of these TCs, leading to a weak relationship between latitudinal position and Niño-3 index at the seasonal time scales. In fact, even for the annual-average data, whether the relationship between latitudinal distance of TCs and Niño-3(DJF) is significant or not heavily depends on the location (i.e., in the Northern Hemisphere or the Southern Hemisphere) and season of TCs (not shown).

To quantitatively measure the magnitudes of TCrelated wind stresses, Fig. 6 compares the composite surface winds of TCs in both hemispheres from the IBTrACS (Figs. 6a,b) and ERA-Interim (Figs. 6c,d) datasets. The composite is based on TCs that are associated with a strong equatorial westerly (Fig. 2c). At first glance, the structure and magnitude of anomalous surface winds associated with TCs from these two datasets are similar, indicating that TCs identified from ERAInterim are highly similar to those from IBTrACS in their frequency and spatial distribution (Lian et al. 2018). Because the latitude of the composite TC center is $\sim 9^{\circ}$ from the equator for TCs in both hemispheres, the anomalous wind at $\sim 10^{\circ}$ equatorward from the $\mathrm{TC}$ center is at the equator, with a speed $>6.5 \mathrm{~m} \mathrm{~s}^{-1}$ at the longitude of the TC.

Given the statistical results presented above, the parameterization of the multiplicative TCs used in the model is set as follows. The timing of each TC is purely random. At each model step, we generate a random 


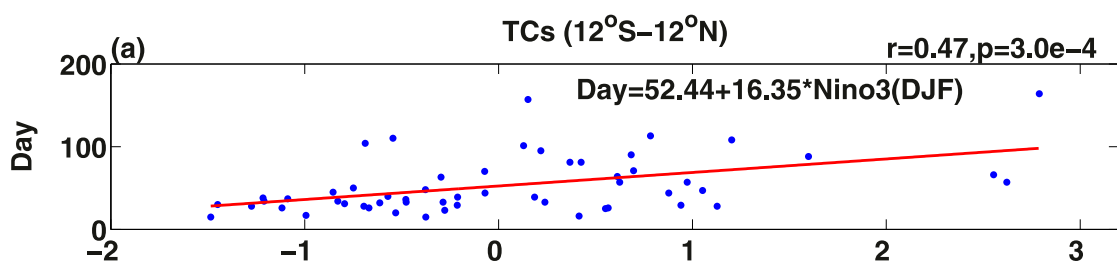

(b) $\quad r=0.57, p=4.4 e-6$
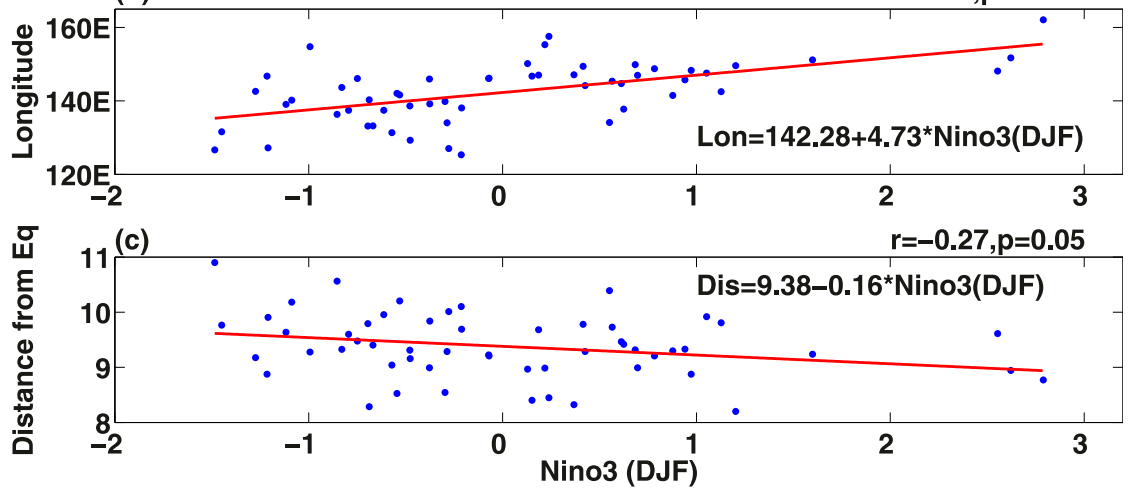

FIG. 4. Scatterplot of (a) annual-integrated number of TC days and annual-average (b) TC longitude and (c) TC latitudinal distance from the equator against the Niño-3 (DJF) index. The linear regression expression is given in each panel; red lines indicate that the regression coefficient is significantly different from zero at the 95\% confidence level (Student's $t$ test). Numbers at the top right denote the correlation coefficient and $p$ value.

number $p$. If $p$ is smaller than the probability of TC presence, which is modeled as $P=P_{0}+P_{1} \times$ Niño-3, a 10 -day TC is added to the model wind stress field. Here, $P_{0}$ and $P_{1}$ are set to 0.15 and 0.03 , respectively, so that the average number of TC days is 4.5 days per month and increases (decreases) by 1.0 day per month with a $1^{\circ} \mathrm{C}$ increase (decrease) in the Niño-3 index, as in the observations (Fig. 5a). The mean longitude of TCs is set
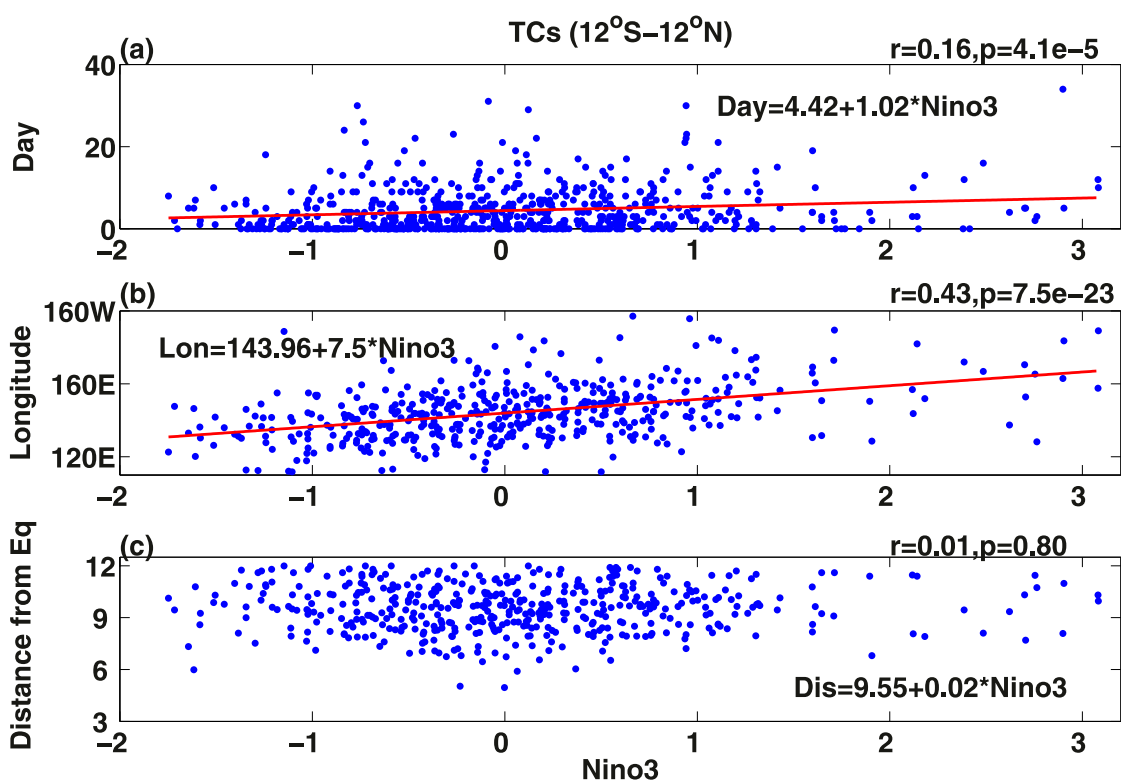

FIG. 5. Scatterplot of (a) monthly integrated number of TC days, (b) monthly average TC longitude, and (c) monthly average TC latitudinal distance from the equator against the monthly Niño-3 index. The linear regression expression is given in each panel. Red lines indicate that the regression coefficient is significantly different from zero at the $95 \%$ confidence level (Student's $t$ test). Numbers at top right denote the correlation coefficient and $p$ value. 


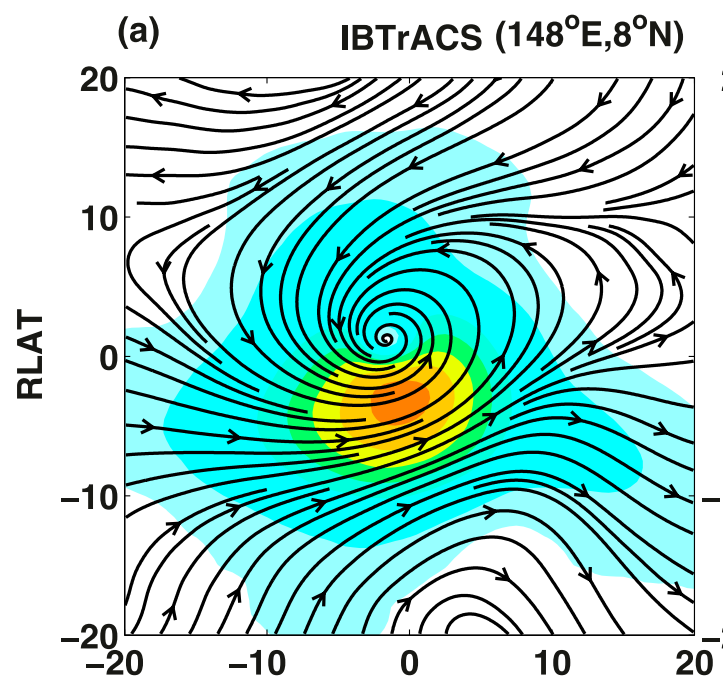

(c) ECMWF $\left(147^{\circ} \mathrm{E}, 9^{\circ} \mathrm{N}\right)$
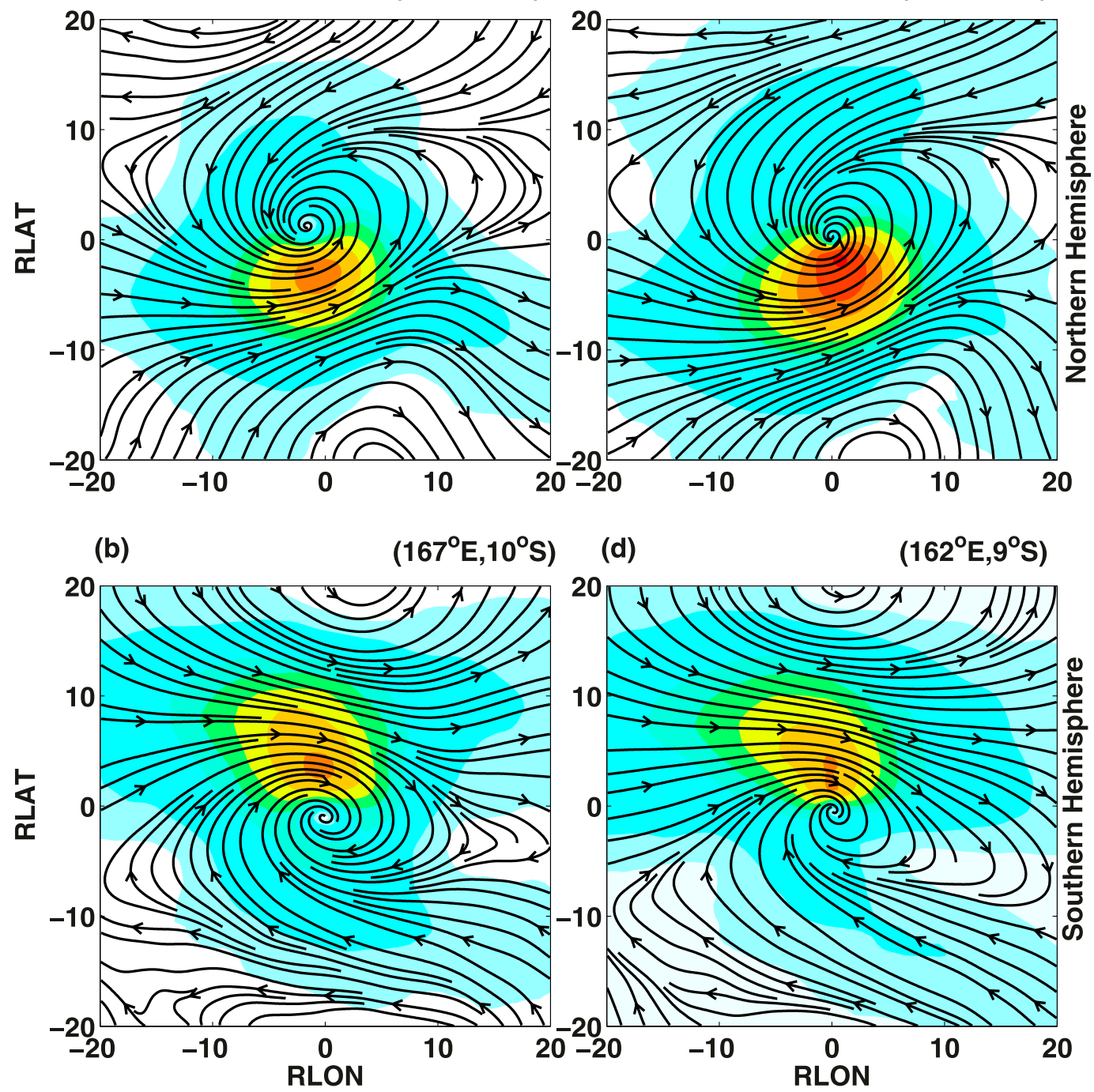

(d)

$\left(162^{\circ} \mathrm{E}, 9^{\circ} \mathrm{S}\right)$
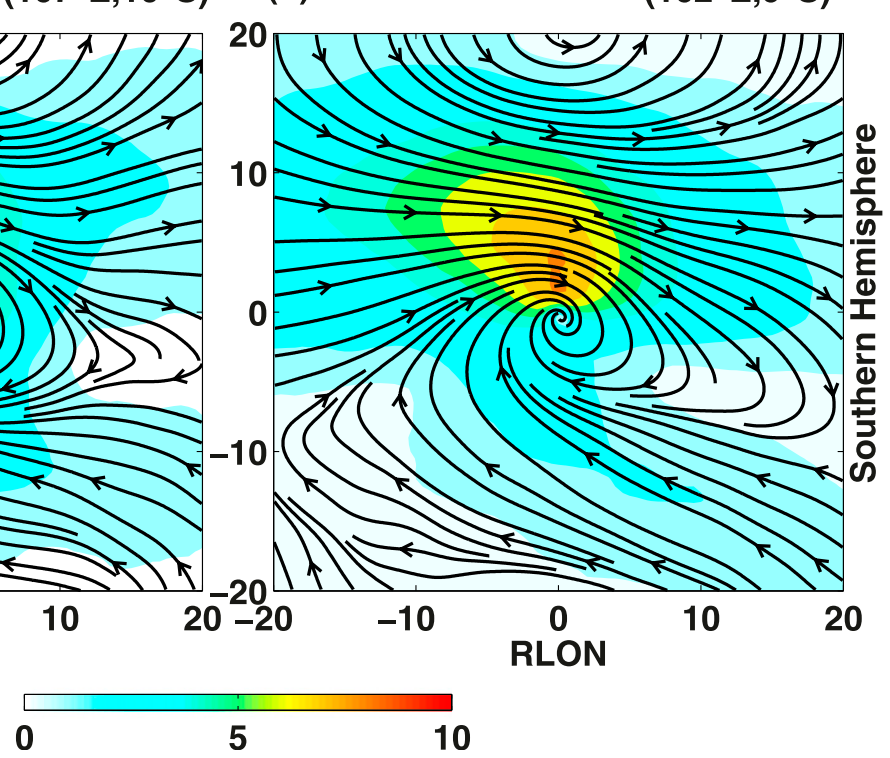

FIG. 6. Composite surface wind of TCs in both hemispheres using (a),(b) TCs from IBTrACS and (c),(d) TCs tracked from the ERA-Interim dataset. The composite is based on TCs that are associated with a strong equatorial westerly. Colors and contours indicate the anomalous wind speed $\left(\mathrm{m} \mathrm{s}^{-1}\right)$ and the streamfunction, respectively. The abscissa is the relative longitude (RLON) and relative latitude (RLAT); $\left(0^{\circ}, 0^{\circ}\right)$ represents the TC center. The longitude and latitude of the composite TC center are given at the top right of each subfigure.

to $145^{\circ} \mathrm{E}$, and the longitude of the modeled TC is parameterized as lon $=145+7.5 \times$ Niño-3 (Fig. 5b). Given the fact that TCs that are associated with strong equatorial westerlies originate mainly in the Northern Hemisphere (Fig. 3b), the latitude of TCs is fixed at $10^{\circ} \mathrm{N}$. The radius of TCs is set at $13.0^{\circ}$ so that TC-related large-scale wind stresses can reach the equator (Fig. 6). Note that as the zonal resolution of model is coarse $\left(5.625^{\circ}\right)$, the structures of two TCs with different longitudes may not be identical to each other. However, as the radius of the superimposed $\mathrm{TC}$ is large, a small change in TC structure during the model integration will not significantly affect the model results.

As shown in Fig. 6, the equatorial surface anomaly associated with TCs is greater than $6.5 \mathrm{~m} \mathrm{~s}^{-1}$ at the longitude of the TC. Using a drag coefficient of $2.20 \times 10^{-3}$, the equatorial wind stress anomaly associated with TCs is about $0.12 \mathrm{~N} \mathrm{~m}^{-2}$. However, reanalysis products generally underestimate surface wind speeds associated with TCs, and the drag coefficient under extreme wind 


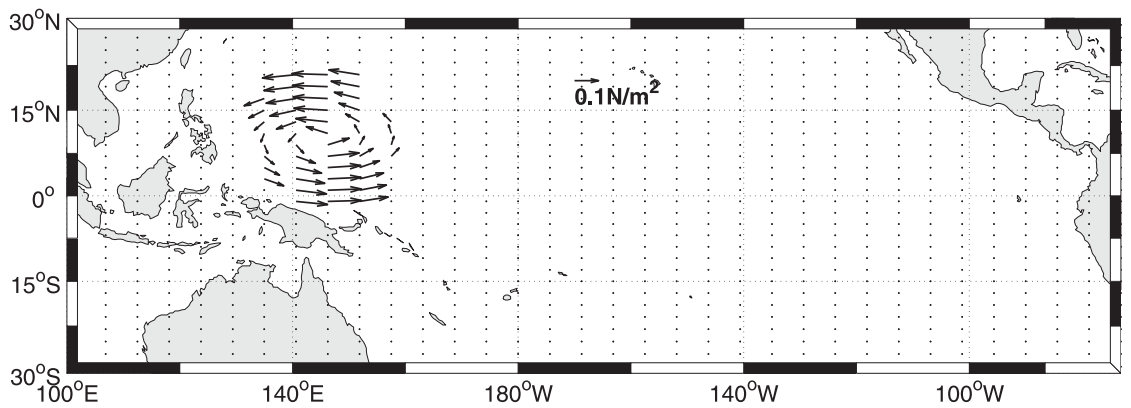

FIG. 7. Model domain and structure of TC-related wind stresses added to the model. The latitude of the TC is fixed at $10^{\circ} \mathrm{N}$, with the mean longitude at $145^{\circ} \mathrm{E}$.

conditions is expected to be much stronger than $2.20 \times$ $10^{-3}$ (e.g., Hsu et al. 2017). We therefore set the magnitude of TC-related wind stresses to $0.20 \mathrm{~N} \mathrm{~m}^{-2}$ in the model. Figure 7 presents the structure of TC-related wind stresses added to the model. The sensitivity of our results to the TC parameterization will be discussed in section 6.

\section{Effect of TCs on ENSO dynamics}

We first compare the evolution of equatorial SST anomalies in the ZC, Ctrl, TC-Alone, and TC-Full runs. As shown by Zebiak and Cane (1987), ENSO in the ZC run is aperiodic and irregular, with a maximum SST anomaly of about $2.5^{\circ} \mathrm{C}$ in the eastern equatorial Pacific (Fig. 8a). When the coupling strength is reduced, the modeled ENSO in the Ctrl run tends to be periodic but with much smaller magnitude (Fig. 8b). When air-sea coupling is switched off in the model and forced by highfrequency TC-related wind stresses alone, there is no ENSO signal in the model (Fig. 8c), indicating that lowfrequency air-sea coupling is indispensable to ENSO genesis. Finally, in the TC-Full run, in which the TCrelated wind stresses are added to the model wind stress field, the aperiodic and irregular ENSO-like events reappear, with a maximum ENSO magnitude comparable to that of the ZC run (Fig. 8d). Note that as found in the $\mathrm{ZC}$ run, ENSO simulated in the TC-Full run exhibits multidecadal variability. Table 2 lists the STD and skewness of Niño-3 index in the ZC, Ctrl, TC-Alone, and TC-Full runs and from observations. Adding the TC-related wind stresses to the model greatly increases
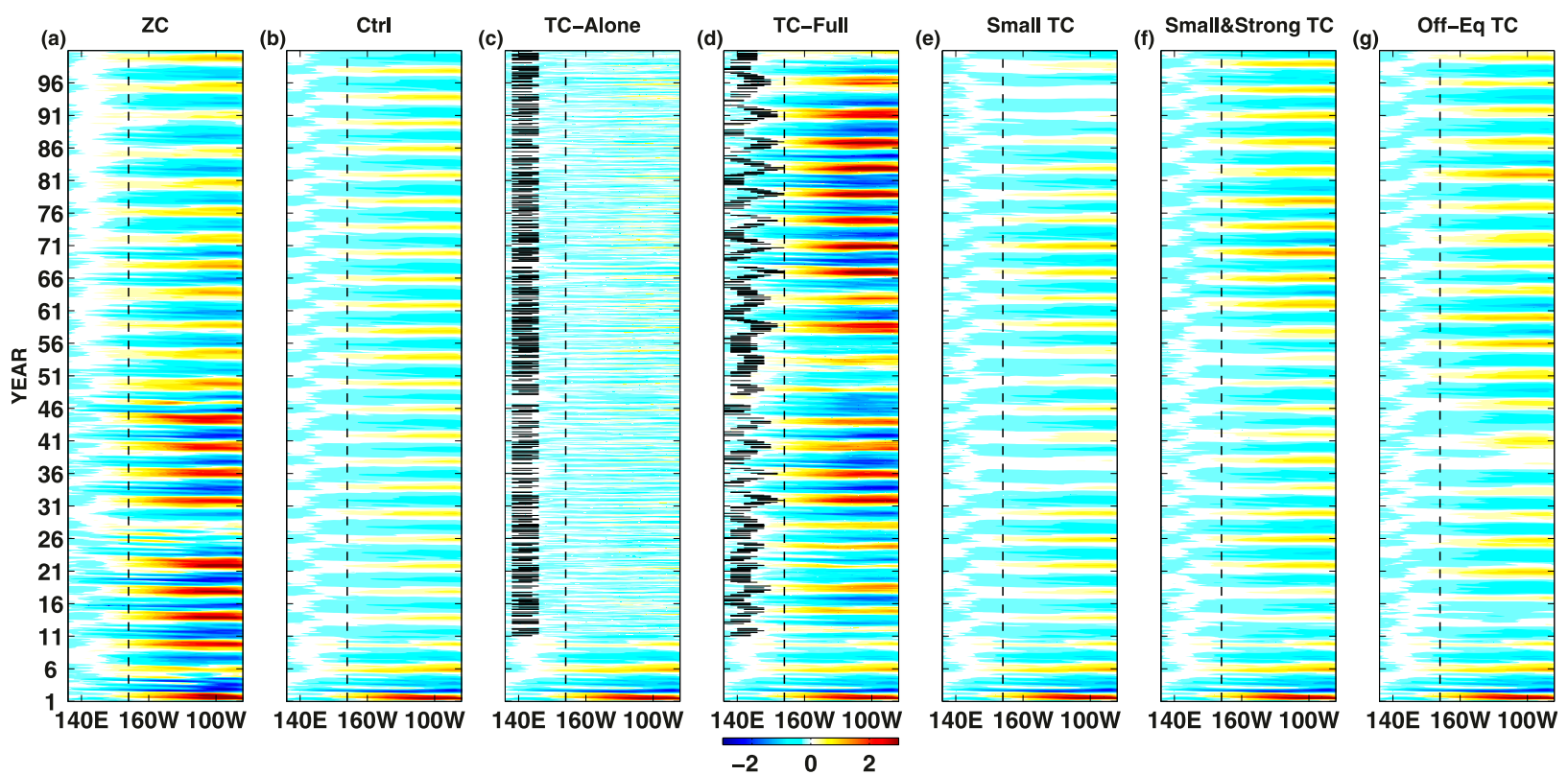

FIG. 8. Evolution of equatorial $\left(5^{\circ} \mathrm{S}-5^{\circ} \mathrm{N}\right) \mathrm{SST}$ anomalies in the (a) ZC, (b) Ctrl, (c) TC-Alone, (d) TC-Full, (e) Small-TC, (f) Small- and Strong-TC, and (g) Off-Eq-TC runs from year 1 to 100. The time step of the model is 10 days. Black lines in (c) and (d) denote TC-related wind stresses. 
TABLE 2. STD and skewness of the Niño-3 index in the ZC, Ctrl, TC-Alone, and TC-Full runs and from observations. For each experiment, the model is integrated for 200 years. The record length in observation is 55 years.

\begin{tabular}{lcc}
\hline \hline Experiment & Niño-3 STD & Niño-3 skewness \\
\hline ZC run & 1.08 & 0.86 \\
Ctrl run & 0.32 & 0.53 \\
TC-Alone run & 0.17 & 0.56 \\
TC-Full run & 1.07 & 0.68 \\
Obs & 0.84 & 0.75 \\
\hline
\end{tabular}

the variation and skewness of the Niño-3 index, leading to STD and skewness of Niño-3 index in the TC-Full run that are closer to observations when compared with the other runs.

Figures $8 \mathrm{e}-\mathrm{g}$ show the evolution of SST anomalies for the Small-TC, Small- and Strong-TC, and Off-Eq-TC runs. It is clear that the magnitude and irregularity of the modeled ENSOs are very weak once the TC-related wind stresses are away from the equator. The standard deviation of Niño-3 index in the Small-TC, Small- and Strong-TC, and Off-Eq-TC runs are 0.31, 0.45, and 0.44, respectively. These values are close to that from the Ctrl run, but much smaller than that from the TC-Full run

A case study is shown in Fig. 9 to characterize ENSO dynamics in the presence of TCs. In year 24 of the TCFull run, eight TCs are found in the western Pacific. These TCs excite strong eastward surface current anomalies (Fig. 9a) and downwelling Kelvin waves (Fig. 9b) across the equatorial Pacific a few days after their occurrence, both of which are favorable conditions for El Niño growth (Fig. 9d). With the growth of the El Niño in year 24, the off-equatorial thermocline shoals in the central-eastern Pacific and propagates westward as the upwelling Rossby waves (Fig. 9c). This weak low-frequency shoaling of the off-equatorial thermocline depth manifests the classic discharge process of equatorial upper-ocean heat content during the El Niño in the model (Jin 1997). At the same time, the eight TCs excite strong upwelling Rossby waves in the western off-equatorial regions (Fig. 9c). These strong upwelling Rossby waves reinforce the weak lowfrequency upwelling Rossby waves that propagated from the central-eastern off-equatorial Pacific, and reach the western equatorial Pacific at the beginning of year 25 (Fig. 9b).

There are three TCs in the model in year 25, and each of them excites strong eastward advection (Fig. 9a). However, as the thermocline in the western equatorial Pacific was severely shoaled early in year 25 , the downwelling Kelvin waves excited by these three TCs do not significantly influence the equatorial thermocline depth anomaly, which is negative along the equator though year 25 (Fig. 9b). A La Niña event is found at the end of the year (Fig. 9d). With the development of this La Niña event, the off-equatorial thermocline in the centraleastern Pacific deepens and propagates westward as the downwelling Rossby waves (Fig. 9c). The deepening of the off-equatorial thermocline depth manifests the recharge process of equatorial upper-ocean heat content during the La Niña in the model. The downwelling Rossby waves reach the western boundary around April of year 26 and reflect as the downwelling Kelvin waves in the equatorial Pacific (Fig. 9b).
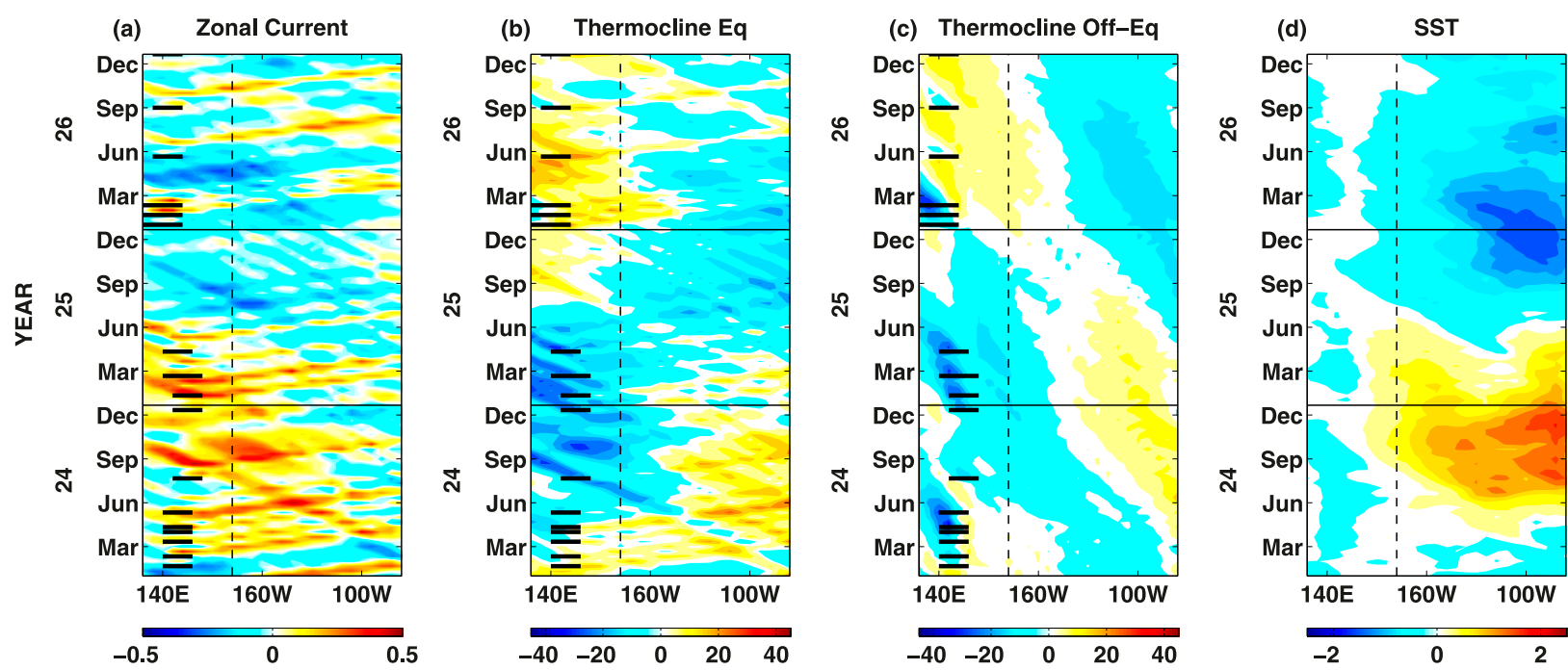

FIG. 9. Longitude-time plots of (a) equatorial $\left(5^{\circ} \mathrm{S}-5^{\circ} \mathrm{N}\right)$ zonal current anomaly, (b) equatorial thermocline depth anomaly, (c) offequatorial $\left(7^{\circ}-13^{\circ} \mathrm{N}\right)$ thermocline depth anomaly, and (d) equatorial SST anomaly from year 24 to 26 of the TC-Full run. Black lines denote TC-related wind stresses. 

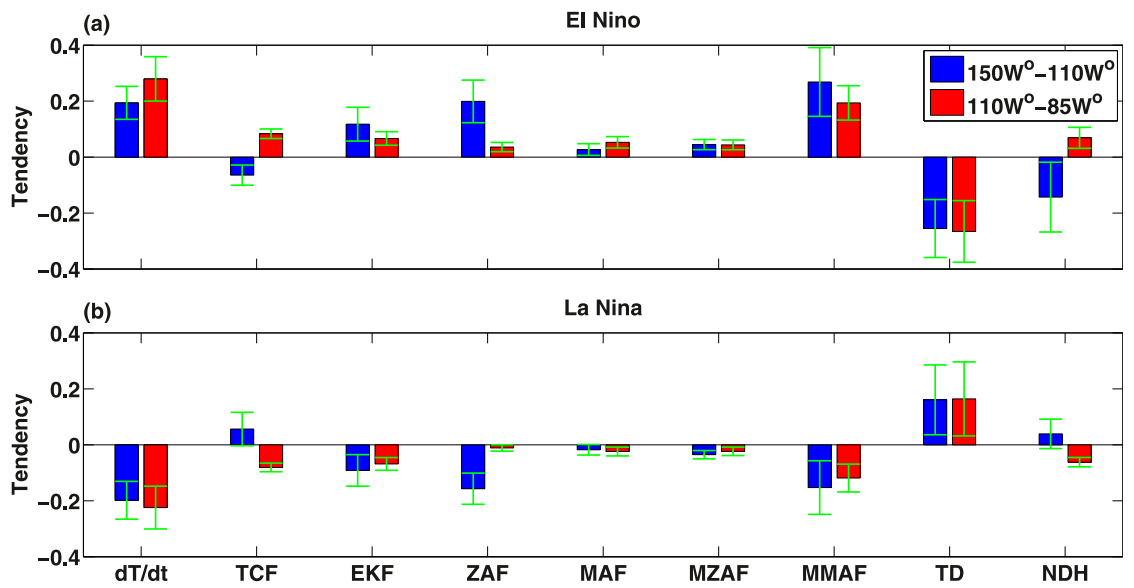

FIG. 10. Surface-layer heat budgets $\left({ }^{\circ} \mathrm{C}\right.$ month ${ }^{-1}$ ) of (top) El Niño and (bottom) La Niña simulated in the TC-Full run. Blue and red bars denote the budget averaged in regions $150^{\circ}-110^{\circ} \mathrm{W}, 5^{\circ} \mathrm{S}-5^{\circ} \mathrm{N}$ and $110^{\circ}-85^{\circ} \mathrm{W}, 5^{\circ} \mathrm{S}-5^{\circ} \mathrm{N}$, respectively. The budget is averaged over the 12 months before an event reaches its maximum. Error bars indicate one STD.

The deepening thermocline in the western equatorial Pacific early in year 26 is even stronger than that in year 24 (Fig. 9b). However, as there are only two TCs after April in year 26, the equatorial thermocline does not deepen enough to excite an El Niño and the eastern equatorial Pacific remains in a cooling phase through the remainder of year 26. It should be noted that if more TCs were randomly generated in year 26, a neutral ENSO phase could be induced instead (will be shown in Fig. 14d). The above case study indicates that the ENSO state simulated in this model depends on both the oceanic state (i.e., equatorial thermocline depth) and atmospheric high-frequency forcing (i.e., TC-related wind stress anomalies).

Figure 10 shows the heat budget of the surface-layer temperature tendency in the central-eastern equatorial Pacific $\left(150^{\circ}-110^{\circ} \mathrm{W}, 5^{\circ} \mathrm{S}-5^{\circ} \mathrm{N}\right)$ and far eastern equatorial Pacific $\left(110^{\circ}-85^{\circ} \mathrm{W}, 5^{\circ} \mathrm{S}-5^{\circ} \mathrm{N}\right)$ in El Niño and La Niña years in the TC-Full run. During El Niño events, TCF and MMAF are the two primary contributors to warming growth in the far eastern equatorial Pacific, whereas EKF, ZAF, and MMAF dominate SST warming in the central-eastern equatorial Pacific (Fig. 10a). In both regions, the TD term is the primary damping term. Other terms such as MAF, MZAF, and NDH play a less important role in the model. During La Niña events, the relative contributions of these terms are almost the same as during El Niño events but with the opposite sign (Fig. 10b). The relative contribution of these terms to El Niño and La Niña growth is consistent with observations (Santoso et al. 2017).

To further investigate which terms change heavily during El Niño growth with the adding of TCs, Fig. 11 compares the heat budget during the modeled El Niño from the Ctrl and TC-Full runs. Because El Niño simulated in the TC-Full run is much stronger than that in the Ctrl run (Fig. 8), each term in the heat budget is normalized by the total tendency $(d T / d t)$. Although the changes are not statistically significant in most terms, adding TCs indeed increases the EKF, ZAF, and MMAF in the central equatorial Pacific (Fig. 11a). In the far eastern equatorial Pacific, the main difference is from the NDH term (Fig. 11b). Further analysis reveals that the growth of NDH during El Niño growth in the TC-Full run is primarily caused by the vertical component (not shown). This finding is consistent with Jin et al. (2003), who showed that the vertical NDH is important for strong El Niño growth in the far eastern equatorial Pacific in observations, although uncertainty exists in this term due to inconsistency in difference reanalysis datasets (Lian et al. 2017; Santoso et al. 2017). From Figs. 10 and 11, we conclude that TCs increase the amplitude of modeled El Niño events mainly through the TCF, EKF, and ZAF terms, with a noticeable contribution from the NDH term.

\section{Effect of TCs on ENSO prediction and associated uncertainty}

The classic recharge-discharge ENSO theory tells us that before the development of an El Niño (La Niña), the upper-ocean heat content in the equatorial Pacific increases (decreases), as manifested by the deepened (shoaled) equatorial thermocline depth during an El Niño (La Niña) developing year (Jin 1997; Meinen and McPhaden 2000; Ren and Jin 2013). Shown in Fig. 12 are 

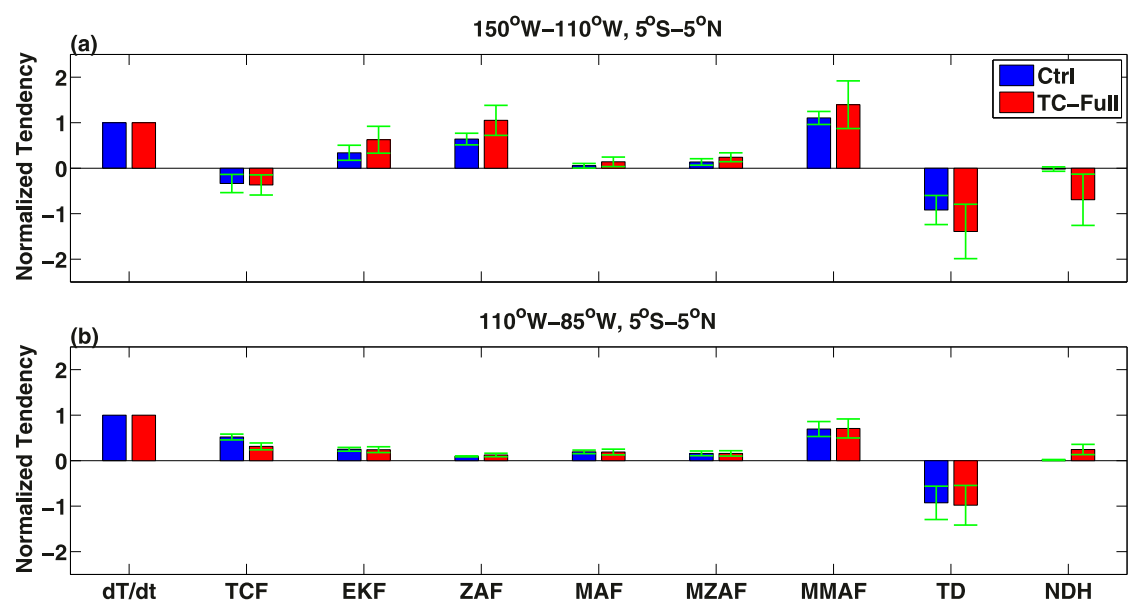

FIG. 11. Composite of normalized surface-layer heat budgets averaged in the central $\left(150^{\circ}-\right.$ $\left.110^{\circ} \mathrm{W}, 5^{\circ} \mathrm{S}-5^{\circ} \mathrm{N}\right)$ and eastern $\left(110^{\circ}-85^{\circ} \mathrm{W}, 5^{\circ} \mathrm{S}-5^{\circ} \mathrm{N}\right)$ equatorial Pacific during El Niño. Blue and red bars denote results from the Ctrl and TC-Full runs, respectively. The budget is averaged over the 12 months before an El Niño reaches its maximum, and each term is normalized by the total tendency $(d T / d t)$. Error bars indicate one STD.

the evolutions of the normalized Niño-3 index and thermocline depth index zonally integrated over the equatorial Pacific in the TC-Full run. As found in observations (Meinen and McPhaden 2000; Horii et al. 2012), the equatorial thermocline depth index leads the Niño-3 index by almost one-quarter of the ENSO cycle. The maximum correlation between the two time series is 0.73 (significant at the $99 \%$ confidence level) and occurs when the equatorial thermocline depth index leads the Niño-3 index by 14 months, suggesting that ocean memory is the main source of ENSO prediction (C. Chen et al. 2016).

Despite the high correlation between the two time series at long lead times, using the equatorial thermocline depth alone is insufficient to predict subsequent ENSO event. Figure 13 compares the evolutions of SST anomaly and TC-related wind stresses along the equator in the TCFull run and three 24-month forecasts starting in January of year 23. In the TC-Full run, there are four TCs in year 23. Two of them occur before April and the other two occur in November (Fig. 13a). A weak warming anomaly is found around the equatorial date line in March of year 23 , and a weak cooling anomaly is found in the centraleastern equatorial Pacific at the end of the year. The Niño-3 index at the end of year 23 is $-0.41^{\circ} \mathrm{C}$. In year 24 , there is a strong El Niño. Dynamical processes of this strong El Niño were discussed in the previous section (cf. Fig. 9).
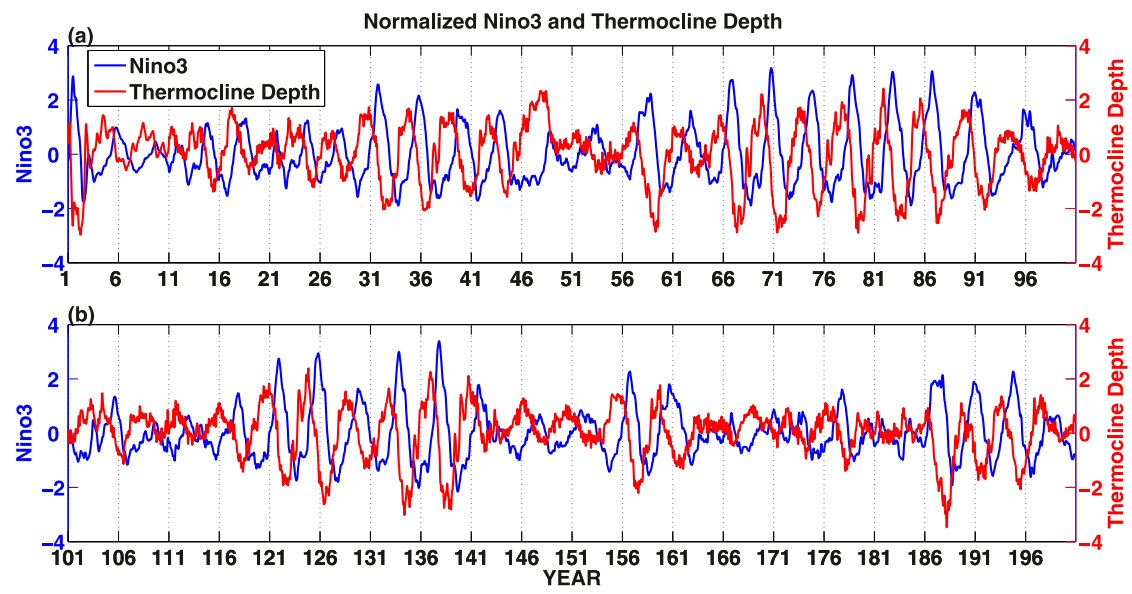

FIG. 12. Evolution of the normalized Niño-3 index (blue) and equatorial thermocline depth anomaly (red) in the TC-Full run. 

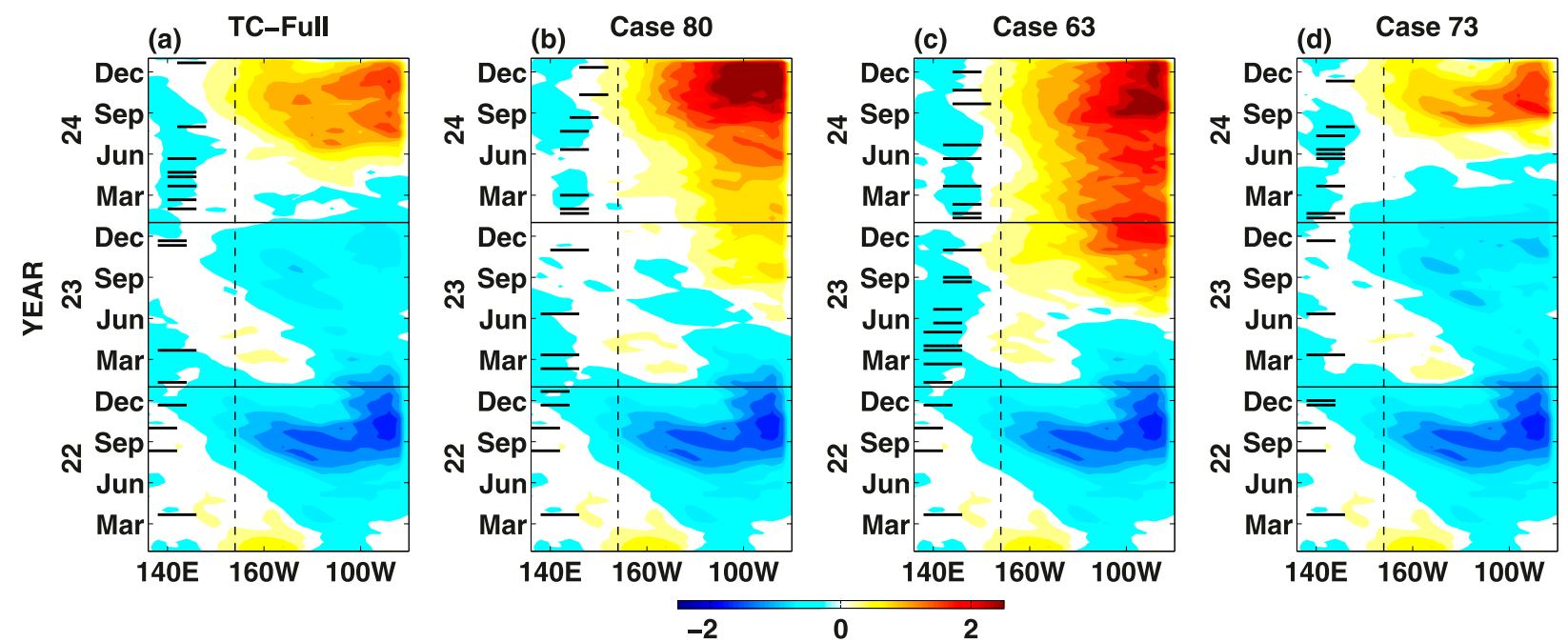

FIG. 13. Longitude-time plots of equatorial $\left(5^{\circ} \mathrm{S}-5^{\circ} \mathrm{N}\right)$ SST anomalies (colors) and TC-related wind stresses (thick black lines) from (a) year 22 to 24 of the TC-Full run and (b)-(d) three 24-month forecasts beginning in January of year 23.

Shown in Fig. 13b are the evolutions of the SST anomaly and TC-related wind stresses in case 80 from the Ensemble-TC-forecast run. The number of TCs in year 23 is the same as in the TC-Full run, but the timing of these TCs differs. The interval between the first two TCs in spring of year 23 is shorter, and the third TC occurs around June. The warm SST anomaly around the equatorial date line in late spring of year 23 is stronger in case 80 compared with the TC-Full run. Some studies have argued that strong equatorial westerlies occurring in early summer are more likely to induce warming anomalies in the eastern equatorial Pacific at the end of the calendar year because the seasonal upwelling in this region is strongest in boreal winter (Chen et al. 2015; Hayashi and Watanabe 2019). Indeed, SST anomalies in the central-eastern Pacific become positive from May in year 23. The Niño-3 index at the end of year 23 is $0.55^{\circ} \mathrm{C}$. The warming further develops in year 24 , and a super El Niño is induced later in the year. The sharp difference in SST anomalies at the end of year 23 between the TC-Full run and case 80 indicates that the ENSO state in a given year may depend on the timing of TCs during the year.

The ENSO state at the end of year 23 also depends on the number of TCs. Figures $13 \mathrm{c}$ and $13 \mathrm{~d}$ show the SST anomaly and TC-related wind stresses for cases 63 and 73 , respectively. In case 63, there are 10 TCs in year 23 . These TCs excite stronger eastward warm advections and downwelling Kelvin waves (not shown) than those in the TC-Full run, and thus lead to stronger eastern equatorial Pacific warming at the end of year 23. The Niño-3 index at that time is $1.38^{\circ} \mathrm{C}$. In contrast, there are only three TCs in year 23 in case 73 , and the central-eastern equatorial Pacific is in a cooling state at the end of the year. The Niño-3 index at that time is about $-0.67^{\circ} \mathrm{C}$, much colder than that of the TCFull run.

Figure 14a shows the evolutions of the Niño-3 index in the TC-Full run and the 12-month forecast starting in January of year 23 from the Ensemble-TC-forecast run. With the various numbers and timings of TCs added in year 23, the Niño-3(DJF) index at the end of the year varies from $-0.53^{\circ}$ to $1.37^{\circ} \mathrm{C}$. The spread of the Niño3 (DJF) index at the end of year 23 is $1.90^{\circ} \mathrm{C}$, almost twice the STD of the Niño-3 index in the TC-Full run.

The evolution of the Niño-3 SST anomaly in the TCFull run and the 12-month forecasts starting in January of years 24, 25, and 26 are shown in Figs. 14b-d. Note that there is a full ENSO cycle from year 23 to 26 in the TC-Full run. In all three ensemble forecasts, the Niño-3 index varies over a wide range at the end of the year in which the multiplicative TCs were added. The maximum spread of the Niño-3(DJF) index is $1.91{ }^{\circ} \mathrm{C}$ when forecasts start in January of year 24 (Fig. 14b), whereas the minimum spread is $0.63^{\circ} \mathrm{C}$ when forecasts start in January of year 25 (Fig. 14c). The differing spreads of the Niño-3(DJF) index in the various ensemble forecasts can be explained as follows. The thermocline shoals in the western-central off-equatorial Pacific at the end of year 24 (Fig. 9c), making the equatorial Pacific in the discharge phase at the beginning of year 25 (Fig. 9b). Low-frequency air-sea interactions thus provide favorable conditions for a La Niña event. Given the statistical relationship between ENSO and the probability of TC presence used in the model $\left(P=P_{0}+P_{1} \times\right.$ Niño-3, where $P_{0}$ and $P_{1}$ are set to 0.15 and 0.03 , respectively), 

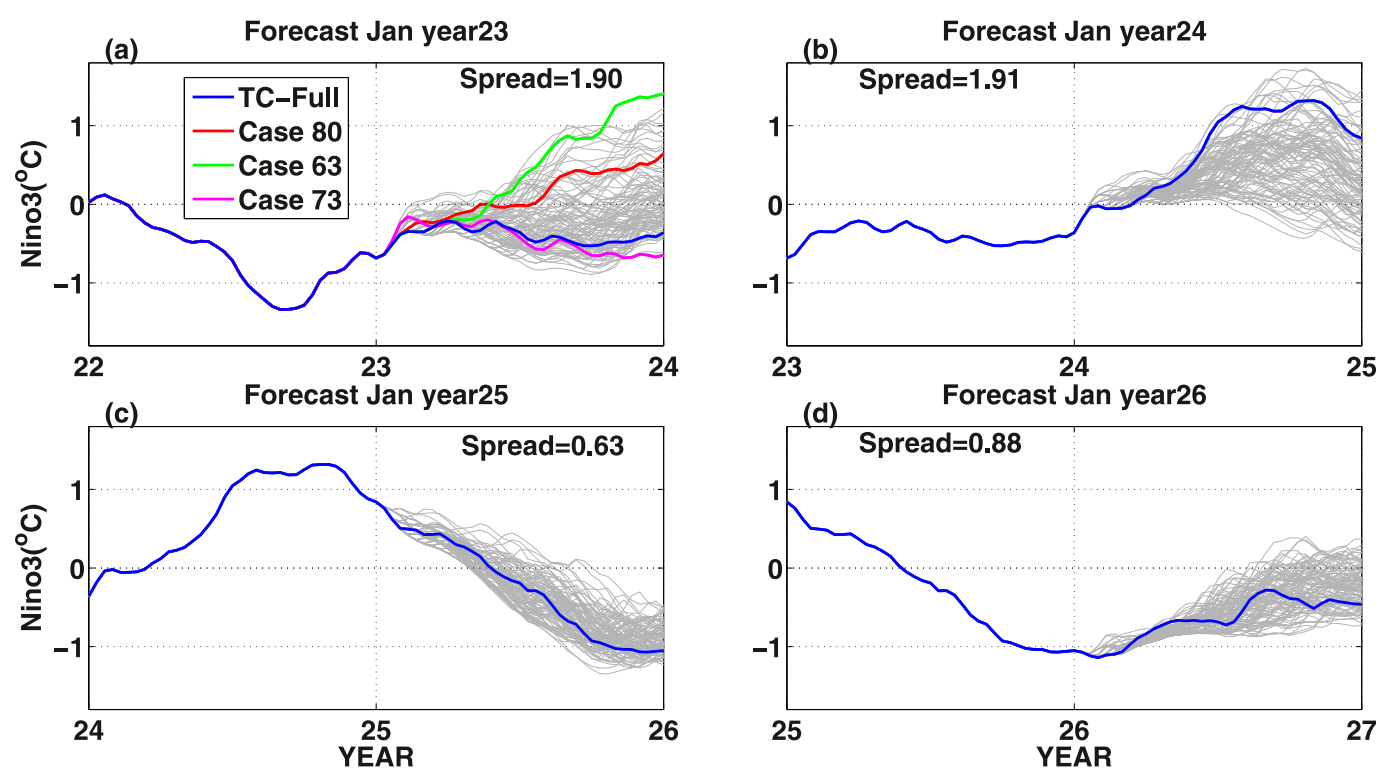

FIG. 14. Evolution of the Niño-3 index in the TC-Full run (blue lines) and a 12-month forecast starting in January of year (a) 23, (b) 24, (c) 25, and (d) 26 from the Ensemble-TC-forecast run.

the number of TCs in year 25 gets smaller, as does the uncertainty in the number and timing of TCs in the 100member ensemble. In other words, the number and timing of TCs in the 100-member ensemble vary in a narrow range. On the other hand, the equatorial Pacific is in a recharge phase at the beginning of year 24 (Fig. 9b), and the system tends to be in a warm ENSO state in year 24 . The probability of TC presence thus increases, making the number and timing of TCs in the 100 -member ensemble vary in a broad range. Given the strong influence of TCs on ENSO, the broad (narrow) ranges in the number and timing of TCs in a given year lead to larger (smaller) uncertainty in the final ENSO state at the end of the year. Therefore, the spread of the Niño-3 forecasts beginning in January of year 24 is much greater than for those beginning in January of year 25 .

In fact, we estimate the spread of all El Niño and La Niña events at 12-month lead time in the EnsembleTC-forecast run. The mean spread of the Niño-3(DJF) index in El Niño and La Niña years is $1.78^{\circ}$ and $0.92^{\circ} \mathrm{C}$, respectively. Despite this difference, it is clear that for any ENSO phase (El Niño, La Niña, and neutral), the uncertainty (measured by the spread) in the Niño-3 index at the end of the calendar year is comparable to the STD of the Niño-3 index in the TC-Full run.

Figure 15 further demonstrates the strong influence of the number and timing of TCs on ENSO and its uncertainty. Figure 15a shows scatterplots of the Niño$3(\mathrm{DJF})$ index and number of TC days in the 12-month ensemble forecast starting in January of year 23. The number of TC days is a good indicator of ENSO strength at the end of the year. In general, more (fewer) TC days are associated with a warmer (colder) ENSO state in the DJF season; their relationship is significant at the $95 \%$ confidence level. However, for members with the same number of TC days, the Niño-3(DJF) indices vary over a wide range. For example, for the 11 members with 70 TC days in year 23 (green dots in Fig. 15a), the Niño-3(DJF) indices vary from $-0.31^{\circ}$ to $1.04^{\circ} \mathrm{C}$, indicating that the timing of TCs could also play a role in determining the ENSO amplitude or even the final ENSO state.

The correlation coefficients between the Niño-3(DJF) index and the number of TC days in the 12-month ensemble forecasts beginning in January of years 23-26 are 0.67, 0.87, 0.43, and 0.71, respectively (Figs. 15a-d), significant at the $99 \%$ confidence level. The regression coefficients between the two variables are $38.15,48.44$, 64.43 , and 65.06 , respectively, much greater than that of observations, which is 16.35 (Fig. 4a). This seems to suggest that the influence of TCs on ENSO is overestimated in our experiments. However, if we calculate the regression using the combination of scatterplots shown in Figs. 15a-d, the resulting regression coefficient sharply reduces to 18.10 (Fig. 15e), quite close to that of observations. The reduction in regression coefficient can be explained as follows. On the one hand, the range of the predicted Niño-3(DJF) indices for the four years varies considerably. In years 23,24 , and 26 , the ranges of the predicted Niño-3(DJF) indices overlap and cover a range from $-0.60^{\circ}$ to $1.40^{\circ} \mathrm{C}$, whereas the forecast Niño3(DJF) indices in year 25 vary over an almost nonoverlapped range from $-1.17^{\circ}$ to $-0.54^{\circ} \mathrm{C}$. On the other 

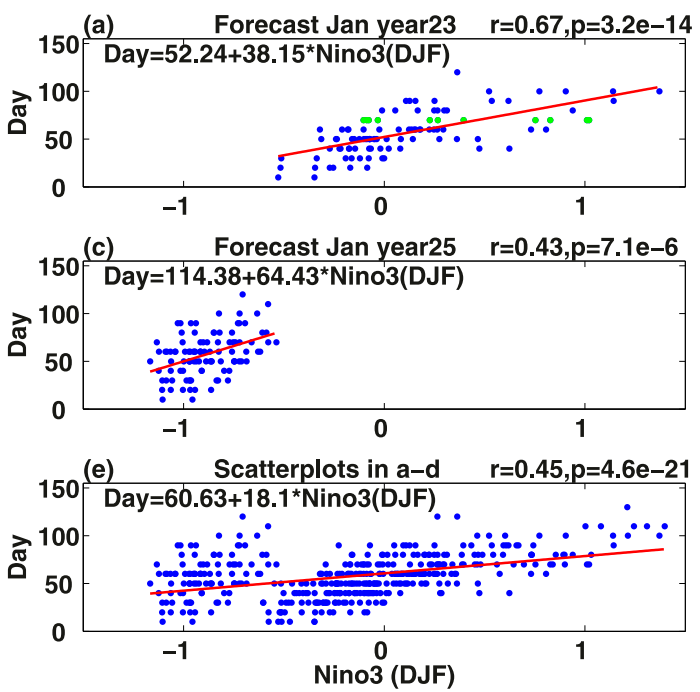

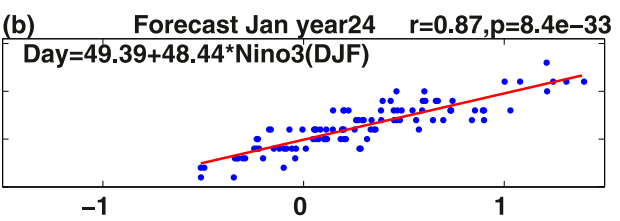

(d) Forecast Jan year26 $\quad \mathrm{r}=0.71, \mathrm{p}=9.7 \mathrm{e}-17$

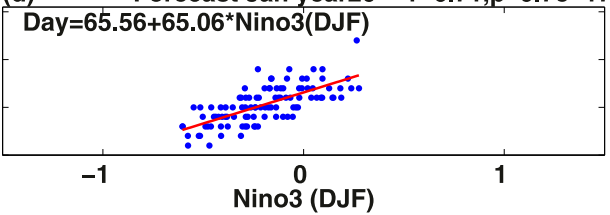

FIG. 15. Scatterplot of annual-integrated number of TC days in the 12-month forecast starting in January of year (a) 23, (b) 24, (c) 25, and (d) 26 against the Niño-3(DJF) index from the Ensemble-TC-forecast run. (e) Scatterplots of the number of TCs and Niño-3 (DJF) shown in (a)-(d). Green dots in (a) denote members with 70 days of TCs added in year 23. The linear regression expression is given in each panel, and the red lines indicate that the regression coefficient is significantly different from zero at the $95 \%$ confidence level (Student's $t$ test). Numbers at the top right denote the correlation coefficient and $p$ value.

hand, the average annual-integrated number of TC days is greater than the variation caused by ENSO (Figs. 4a and 5a). When combining the scatterplots in the four years together, the distribution of the scatterplots shown in Fig. 15e is comparable to those shown in Figs. 15a-d on the $y$ axis but extends farther along the $x$ axis. As a result, the regression coefficient shown in Fig. 15e is much smaller than those shown in Figs. 15a-d.

As a validation of the parameterization of number of TC days used here, we calculate the regression coefficient between the Niño-3 index and monthly integrated number of TC days for the TC-Full run. The average number of modeled TC days is 4.90 days per month, and the regression coefficient between the Niño-3 index and monthly average number of TC days is 0.84 . These values are quite close to the parameters used in the model (cf. Fig. 5a).

We have shown that in this ENSO-TC system, there is a large range of uncertainty in ENSO strength at the end of most of years. For example, El Niño strength at the end of year 23 in case 63 is much greater than that of the TC-Full run (Figs. 13a,c). However, the ENSO in this system is, in fact, highly predictable. Figure 16a shows the evolution of the Niño-3 index for the TC-Full run and that predicted in case 63 from the EnsembleTC-forecast run at a 12-month lead time. El Niño strength is overestimated by case 63 for year 23 and other years (e.g., years 18, 48, and 53). In addition, case 63 incorrectly predicts El Niño events for some years.
For instance, year 48 is a La Niña year in the TC-Full run, but case 63 incorrectly predicts an El Niño in that year. Case 63 also incorrectly predicts an El Niño in year 93, for which a neutral year is found in the TC-Full run. Despite these false alarms, case 63 performs very well overall in predicting other ENSO events present in the TC-Full run. The correlation coefficient between the Niño-3 index in the TC-Full run and that predicted in case 63 at a 12-month lead time is extraordinarily high $(\sim 0.94)$.

Figure 16b shows predictions of the Niño-3 index from the TC-Full run (blue curve) at a 12-month lead time for all 100 members from the Ensemble-TC-forecast run. Again, this ENSO-TC system shows a very high prediction skill for ENSO. The mean correlation coefficient between the Niño-3 index in the TC-Full run and that predicted by the members of the Ensemble-TC-forecast run at a 24 -month lead time reaches 0.80 , with a very narrow spread (Fig. 17a). The root-mean-square error (RMSE) is very small. The mean RMSE at a 24-month lead time is $\sim 0.76$ (Fig. 17b), smaller than STD of the Niño-3 index in the TC-Full run (Table 2). Such a high prediction skill is undoubtedly due to the low-frequency air-sea coupling in the system. However, as the number and timing of TCs added to each member of the Ensemble-TC-forecast run vary, there is a considerable prediction uncertainty for nearly every ENSO event (Fig. 16b). The mean spread of the Niño-3(DJF) index in the Ensemble-TC-forecast run at a 12-month lead time 

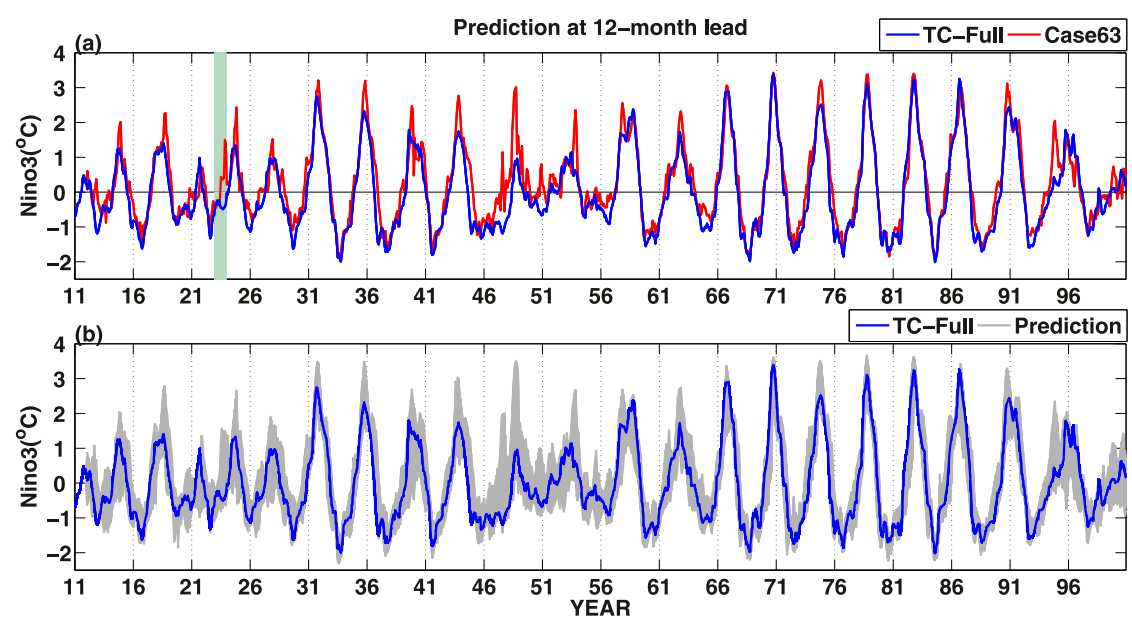

FIG. 16. Evolution of the Niño-3 index in the TC-Full run (blue curve) and as predicted in (a) case 63 and (b) all ensemble numbers with a 12-month lead time from the EnsembleTC-forecast run. The light green bar in (a) denotes year 23.

is $1.24^{\circ} \mathrm{C}$, about $50 \%$ larger than the Niño-3 STD. The mean spreads of the Niño-3(DJF) index in El Niño and La Niña years are $1.78^{\circ}$ and $0.92^{\circ} \mathrm{C}$, respectively. Given these large uncertainties associated with the multiplicative TCs, one cannot reliably predict the strength or even final state of almost every ENSO event at a long lead time (e.g., at 12 months), even though the system itself is highly predictable.

\section{Sensitivity analysis of key parameters}

In this section, we discuss the sensitivity of model results to the parameters used. There are three key parameters that may vary within a prescribed range, including TC-related large-scale wind stress magnitude, number of TC days regarding seasonality, and the drag coefficient. We first discuss the sensitivity to the magnitude of TC-related large-scale wind stress. The default value used for results described in previous sections is $0.20 \mathrm{~N} \mathrm{~m}^{-2}$. Previous studies have shown that wind stresses associated with TCs are difficult to estimate, primarily due to large uncertainties in the drag coefficient (Hsu et al. 2017). The second and third columns in Table 3 list the STD and skewness of the Niño-3 index as a function of TC magnitude. The model settings are identical to those used in the TC-Full run, except for a different TC magnitude. In general, as the TC-related wind stresses intensify the air-sea coupling in the model, the variation of the Niño-3 index increases with TC magnitude. The skewness of the Niño-3 index increases (a)

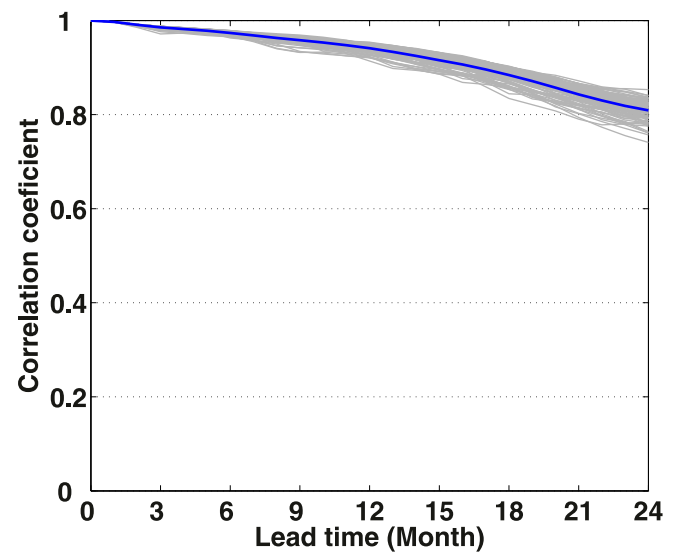

(b)

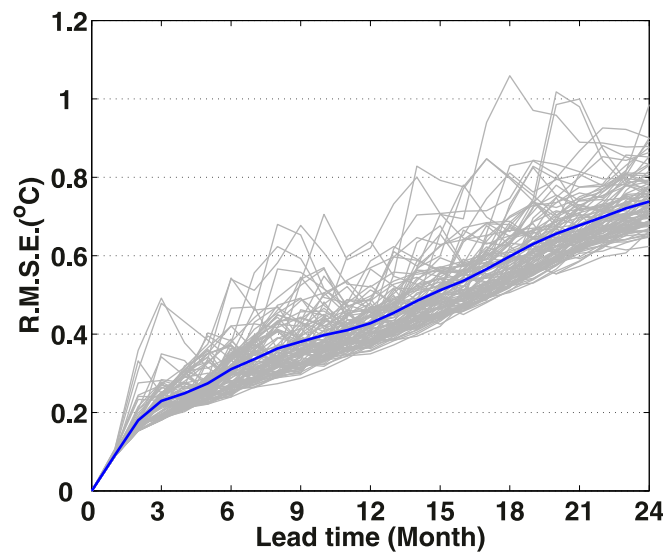

FIG. 17. (a) Correlation and (b) RMSE between the Niño-3 index in the TC-Full run and the EnsembleTC-forecast run as a function of lead time. Blue curves denote the average of the correlations and RMSE curves shown in (a) and (b). 
TABLE 3. STD and skewness of the Niño-3 index, and the spread of the Niño-3(DJF) index in the TC-Full run as a function of TC magnitude $\left(\mathrm{N} \mathrm{m}^{-2}\right)$. Each run is integrated for 200 years.

\begin{tabular}{lccc}
\hline \hline TC magnitude & $\begin{array}{c}\text { Niño-3 } \\
\text { STD }\end{array}$ & $\begin{array}{c}\text { Niño-3 } \\
\text { skewness }\end{array}$ & $\begin{array}{c}\text { Niño-3(DJF) } \\
\text { spread }\end{array}$ \\
\hline 0.00 (Ctrl run) & 0.32 & 0.53 & - \\
0.05 & 0.25 & 0.51 & 0.33 \\
0.10 & 0.47 & 0.92 & 0.79 \\
0.15 & 0.93 & 1.03 & 1.27 \\
0.20 (TC-Full run) & 1.07 & 0.68 & 1.55 \\
0.25 & 1.08 & 0.62 & 1.99 \\
0.30 & 0.95 & 0.32 & 2.27 \\
\hline
\end{tabular}

when TC magnitude changes from 0.05 to $0.15 \mathrm{~N} \mathrm{~m}^{-2}$, and then decreases with stronger TCs. Nevertheless, the STD and skewness of the Niño-3 index are not noticeably different from those of the TC-Full run and observations (Table 2) when the TC magnitude is not large. The last column in Table 3 gives the spread of the Niño-3(DJF) index forecast beginning in January of each year in the Ensemble-TC-forecast run, using various TC magnitudes. Given the strong influence of TCs on ENSO and the increase in STD of the Niño-3 index with TC magnitude, the spread of the Niño3(DJF) index also increases with TC magnitude. Note that for each TC magnitude, the spread of the Niño3(DJF) index is larger than the corresponding STD of the Niño-3 index. Therefore, the large uncertainty in ENSO prediction due to the multiplicative TCs is not sensitive to TC magnitude. It is worth noting that any assessment of ENSO statistics may be influenced by uncertainty caused by insufficient record length (Wittenberg 2009).

As shown in Fig. 14 and Table 3, there is considerable uncertainty in ENSO strength when the prediction starts in January. Previous analyses pointed out that westerly wind bursts exhibit distinct seasonal variations, with more bursts occurring in boreal winter and spring (e.g., Harrison and Vecchi 1997). Accordingly, one may wonder whether uncertainty in ENSO could be reduced if the forecast starts in a season with fewer westerly wind bursts. To this end, we designed three more ensemble forecast runs in which the forecast starts in April, July, and October of each model year. The probabilities of TC presence in these three experiments are different, and increase toward the end of calendar year (Table 4). Other settings used in these three experiments are identical to those of the Ensemble-TC-forecast run. It should be noted that this annual distribution of probability of TC presence is different from that estimated by TCs in the whole western North Pacific $\left(0^{\circ}-\right.$ $\left.40^{\circ} \mathrm{N}\right)$, in which the maximum probability is found around boreal autumn (Knaff et al. 2014). Table 4 shows
TABLE 4. Spread of Niño-3(DJF) indices when forecasts begin in January, April, July, and December of each model year $\left({ }^{\circ} \mathrm{C}\right)$. The probability of TC presence in each experiment is estimated from IBTrACS.

\begin{tabular}{lcccc}
\hline \hline Forecast starting month & Jan & Apr & Jul & Oct \\
\hline Probability & 0.15 & 0.17 & 0.18 & 0.25 \\
Niño-3(DJF) spread & 1.55 & 1.46 & 0.92 & 0.58 \\
\hline
\end{tabular}

the probability of TC presence in the three experiments and the corresponding spread of the Niño-3(DJF) index. Results from the Ensemble-TC-forecast run are also listed. Although the probability gets higher toward the end of calendar year, the spread of the Niño-3(DJF) index steadily decreases with the shortening of forecast period. In the last experiment in which TCs are added from October to December, the spread of the Niño3(DJF) index is reduced to $0.58^{\circ} \mathrm{C}$. However, in the first three experiments in which TCs are added before October, the spread of the predicted Niño-3(DJF) index is comparable to the STD of the Niño-3 index from the TC-Full run, which is $1.07^{\circ} \mathrm{C}$. The results indicate that without a better estimation of TC number and timing before October, the spread of Niño-3(DJF) is always large and one cannot forecast the coming event precisely.

We next test the sensitivity of our results to $C_{d}$, the only parameter that differs from the $\mathrm{ZC}$ run. We conduct a set of Ensemble-TC-forecast runs but using different $C_{d}$ values from $1.4 \times 10^{-3}$ to $3.0 \times 10^{-3}$. In details, for each $C_{d}$ value, we first set up a control run in which the model setting is identical to that in Ctrl run except the $C_{d}$ value. We label these control runs as

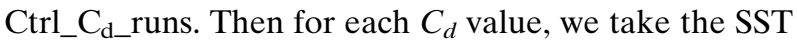
anomaly from the Ctrl_ $\mathrm{C}_{\mathrm{d} \_ \text {run }}$ as the predictand, and predict it by a 100-member ensemble using the same $C_{d}$ value. This set of ensemble forecast run is named the Ensemble-TC-forecast_ $C_{d}$ run. Figure $18 \mathrm{a}$ shows the spread of the forecasted Niño-3(DJF) index when forecasts start in January of each model year as a function of $C_{d}$. In general, the spread of the forecasted Niño3 (DJF) index increases with coupling strength, likely because stronger air-sea coupling amplifies the influence of TCs on ENSO. Figure 18b presents the ratio of forecasted Niño-3(DJF) spread to the STD of the Niño-3 index in Ctrl_C $C_{d \_}$run as a function of $C_{d}$. When $C_{d}$ is smaller than or equal to $2.0 \times 10^{-3}$, the system does not show an ENSO-like oscillation, and the STD of the Niño-3 index in Ctrl_C $C_{d} \_$run is small (not shown). The TCs thus dominate modeled SST variations, leading to a large uncertainty in the forecasted Niño-3 index. The ratio of the Niño-3(DJF) spread to the STD of the Niño-3 index is large in this case. When $C_{d}$ is greater 

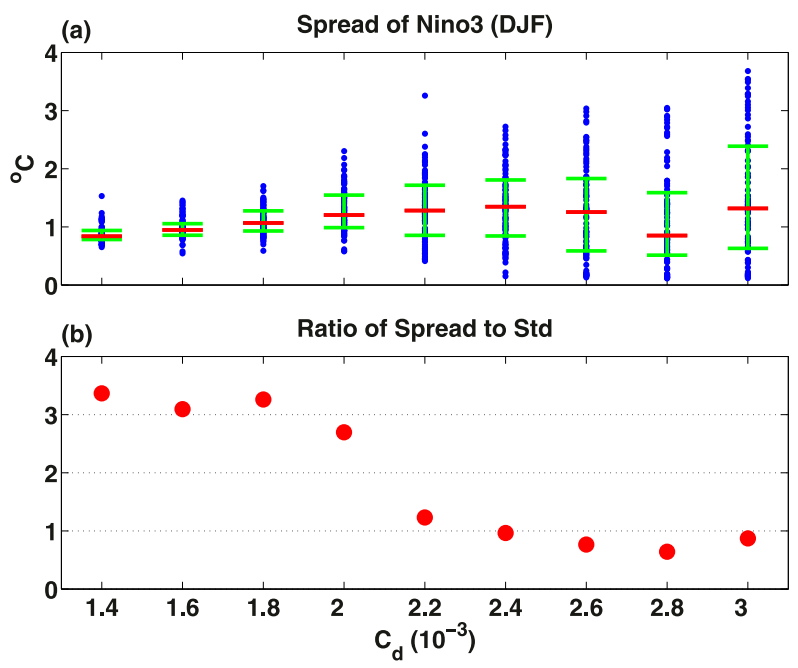

FIG. 18. (a) Spread of the forecasted Niño-3(DJF) index in the Ensemble-TC-forecast_ $\mathrm{C}_{\mathrm{d}}$ run at 12-month lead as a function of drag coefficient $C_{d}$ (blue dots). Green error bars indicate the 25th and 75th percentiles, and red lines indicate the median; (b) ratio of the mean spread of the forecasted Niño-3(DJF) index to the STD of the Niño-3 index in the Ctrl_ $\mathrm{C}_{\mathrm{d} \_}$run as a function of drag coefficient. The Ctrl_ $\mathrm{C}_{\mathrm{d} \_}$run is the control run using model setting identical to those used in Ctrl run except for the drag coefficient. Spread denotes the difference between the maximum and minimum Niño-3(DJF) index among the ensemble forecasts. See text for more details.

than $2.0 \times 10^{-3}$, the modeled Niño-3 index exhibits an ENSO-like oscillation, and the modeled wind stresses are involved in ENSO evolution. In this case, the uncertainty in ENSO predictions depends both on the initial conditions and the multiplicative TCs, and the ratio starts to falls to $\sim 1.0$. These results indicate that the uncertainty in the Niño-3(DJF) index associated with TCs is larger than or at least comparable to the STD of the Niño-3 index if $C_{d}$ varies in a reasonable range.

\section{Conclusions and discussion}

This study investigates the effects of near-equatorial $\left(12^{\circ} \mathrm{S}-12^{\circ} \mathrm{N}\right)$ tropical cyclones over the western Pacific (TCs hereafter) on ENSO using observations and reanalysis data together with model experiments. We find that nearly half of TCs are associated with strong westerly burst-like anomalies in the western and central equatorial Pacific, and that these TCs tend to occur more frequently and move more equatorward and eastward in El Niño years than in La Niña years. When TC-related wind stresses are added to an intermediate model, ENSO events become stronger and more irregular as compared with the results without the TCs. In addition, the STD and skewness of the Niño-3 index with TCs are closer to those of observations. A dynamical analysis shows that the zonal advection feedback (ZAF), Ekman feedback (EKF), and the thermocline feedback (THF) are the three major factors in triggering and maintaining modeled ENSO events in the ENSO-TC system, with a noticeable contribution from the vertical nonlinear dynamical heating (NDH) term.

In this system, both the low-frequency air-sea coupling and the TCs determine the evolution of modeled ENSO. For the majority of modeled ENSO events, their magnitudes and even sometimes their final states during the DJF season heavily depend on the number and timing of TCs added during the ENSO year. Although the classic recharge-discharge process is still evident in the ENSO-TC system, the upper-ocean heat content alone is insufficient to predict subsequent ENSO event at long lead times. Our findings indicate that a real-time ENSO prediction system should include the effects of this atmospheric intraseasonal forcing. Moreover, results suggest that there is an intrinsic bias in unidirectional hybrid dynamical-statistical TC forecast models, because the feedback from statistically predicted TCs on dynamically predicted ENSO state is not considered.

The strong influence of TCs on ENSO provides a practical but challenging means of improving current ENSO prediction skills. State-of-the-art high-resolution general circulation models (GCMs) have demonstrated significant skills in predicting the seasonal activity of TCs in tropical western Pacific [see the review by Camargo and Wing (2016)], including their frequency, geographical distribution, and ACE. Given that ENSO strength is significantly correlated with the frequency of TCs, it is possible that the ENSO prediction skills of climate models can be improved by embedding a regional high-resolution GCM in the modeled tropical Pacific or using an accurate parameterization of TC frequency as, for example, a multiplicative SST-based model component. However, the ENSO magnitude (and sometimes its final state) also depends on the timing of TCs, which cannot be predicted at seasonal time scales at present. Thus, uncertainty in TC timing adds noise to seasonal ENSO forecasts. In other words, ENSO predictability can be improved by modeling TC frequency, but uncertainty in TC timing inevitably leads to considerable unpredictability of ENSO. In this scenario, the ENSO prediction skill depends on the seasonal predictability of TCs.

In this study, the effects of TCs on ENSO are investigated using the intermediate $\mathrm{ZC}$ model. Some wellknown limitations of the ZC model might preclude a comprehensive understanding of the possible influences of TCs on ENSO, particularly those on El Niño diversity and asymmetry between El Niño and La Niña. In the ZC model, the upper-ocean heat content anomaly is an 
essential precondition for the genesis of both El Niño and La Niña (Zebiak and Cane 1987). As the climatological thermocline shoals in the equatorial eastern $\mathrm{Pa}$ cific, the center of the simulated ENSO is biased eastward in the eastern equatorial Pacific when compared with observations (Duan et al. 2014). When the strong equatorial westerly anomalies associated with TC are added to the model, El Niño becomes stronger but the warming center is still located in the far eastern equatorial Pacific. The strong dependence of SST variations on thermocline depth in the eastern equatorial Pacific thus prohibits the genesis of warm-pool El Niño events, which peak near the equatorial date line (Kug et al. 2009). In addition, a series of recent observational analyses show that upper-ocean heat content prior to boreal summer appears to be a better precursor for $\mathrm{La}$ Niña than for El Niño (Neske and McGregor 2018; Planton et al. 2018), with the latter being more relevant to westerly wind bursts in the boreal spring and summer seasons (Santoso et al. 2017). The strong dependence of modeled El Niño and La Niña on the upper-ocean heat content thus reduces the asymmetry in modeled ENSO. In future work, the use of a more detailed GCM might reveal whether the TC induces spatial asymmetry between El Niño and La Niña (e.g., Fedorov et al. 2015).

Finally, it should be noted that only the effects of TCrelated large-scale wind stresses on ENSO have been investigated in the current study. Heavy precipitation, strong surface mixing, and local upwelling can also be induced by TCs (Chan 2000; Korty et al. 2008; Zhang et al. 2018), and these processes might place influences on ENSO as well (Sobel and Camargo 2005; Fedorov et al. 2010). Further study of these processes using more observations and GCM experiments will undoubtedly provide a more comprehensive assessment of the possible effects of TCs on ENSO. The GCM experiments will also help with deep understanding of TCs on ENSO prediction if accurate preconditions of TCs (e.g., largescale Pacific environmental background relative humidity, vertical shear), rigorous initial conditions/perturbations, and data assimilation schemes can be designed and supplemented in models. We expect to deal with these issues in forthcoming work.

Acknowledgments. All data analyzed here are openly available. The ERSST3 data are from https:// climatedataguide.ucar.edu/climate-data/sst-data-noaaextended-reconstruction-ssts-version-3-ersstv3-3b, the IBTRACS dataset is from http://www.ncdc.noaa.gov/ ibtracs/index.php? name = wmo-data, and the ERAInterim reanalysis is from http://apps.ecmwf.int/datasets/ data/interim-full-daily. This work is supported by grants from the Zhejiang Provincial Natural Science Foundation of China (LR19D060001), the China Ocean Mineral Resources Research and Development Association program (DY135-E2-3-01), and the National Natural Science Foundation of China (41690121, 41690120, 41621064).

\section{REFERENCES}

Camargo, S. J., and A. H. Sobel, 2005: Western North Pacific tropical cyclone intensity and ENSO. J. Climate, 18, 29963006, https://doi.org/10.1175/JCLI3457.1.

, and A. A. Wing, 2016: Tropical cyclones in climate models. Wiley Interdiscip. Rev.: Climate Change, 7, 211-237, https:// doi.org/10.1002/wcc.373.

— A. H. Sobel, A. G. Barnston, and P. J. Klotzbach, 2010: The influence of natural climate variability on tropical cyclones, and seasonal forecasts of tropical cyclone activity. Global Perspectives on Tropical Cyclones, J. C. L. Chan and J. D. Kepert, Eds., World Scientific, 325-360, https://doi.org/10.1142/ 9789814293488_0011.

Chan, J. C. L., 2000: Tropical cyclone activity over the western North Pacific associated with El Niño and La Niña events. J. Climate, 13, 2960-2972, https://doi.org/10.1175/15200442(2000)013<2960:TCAOTW > 2.0.CO;2.

, 2005: Interannual and interdecadal variations of tropical cyclone activity over the western North Pacific. Meteor. Atmos. Phys., 89, 143-152, https://doi.org/10.1007/S00703-0050126-Y.

Chand, S. S., J. L. McBride, K. J. Tory, M. C. Wheeler, and K. J. E. Walsh, 2013: Impact of different ENSO regimes on southwest Pacific tropical cyclones. J. Climate, 26, 600-608, https:// doi.org/10.1175/JCLI-D-12-00114.1.

Chavas, D. R., N. Lin, W. Dong, and Y. Lin, 2016: Observed tropical cyclone size revisited. J. Climate, 29, 2923-2939, https://doi.org/10.1175/JCLI-D-15-0731.1.

Chen, C., M. A. Cane, N. Henderson, D. E. Lee, D. Chapman, D. Kondrashov, and M. D. Chekroun, 2016: Diversity, nonlinearity, seasonality, and memory effect in ENSO simulation and prediction using empirical model reduction. J. Climate, 29, 1809-1830, https://doi.org/10.1175/JCLI-D-15-0372.1.

Chen, D., and Coauthors, 2015: Strong influence of westerly wind bursts on El Niño diversity. Nat. Geosci., 8, 339-345, https:// doi.org/10.1038/ngeo2399.

Chen, L., T. Li, S. K. Behera, and T. Doi, 2016: Distinctive precursory air-sea signals between regular and super El Niño. Adv. Atmos. Sci., 33, 996-1004, https://doi.org/10.1007/s00376016-5250-8.

, B. Wang, and L. Wang, 2017: Formation mechanism for 2015/16 super El Niño. Sci. Rep., 7, 2975, https:/doi.org/ 10.1038/s41598-017-02926-3.

Chiodi, A. M., and D. E. Harrison, 2017: Observed El Niño SSTA development and the effects of easterly and westerly wind events in 2014/15. J. Climate, 30, 1505-1519, https://doi.org/ 10.1175/JCLI-D-16-0385.1.

Dee, D. P., and Coauthors, 2011: The ERA-Interim reanalysis: Configuration and performance of the data assimilation system. Quart. J. Roy. Meteor. Soc., 137, 553-597, https://doi.org/ 10.1002/qj.828.

Duan, W. S., B. Tian, and H. Xu, 2014: Simulations of two types of El Niño events by an optimal forcing vector approach. Climate Dyn., 43, 1677-1692, https://doi.org/10.1007/s00382013-1993-4. 
Fedorov, A. V., C. M. Brierley, and K. Emanuel, 2010: Tropical cyclones and permanent El Niño in the early Pliocene epoch. Nature, 463, 1066-1070, https://doi.org/10.1038/nature08831.

- S. Hu, M. Lengaigne, and E. Guilyardi, 2015: The impact of westerly wind bursts and ocean initial state on the development and diversity of El Niño events. Climate Dyn., 44, 13811401, https://doi.org/10.1007/S00382-014-2126-4.

Gao, C., and R.-H. Zhang, 2017: The roles of atmospheric wind and entrained water temperature $\left(\mathrm{T}_{\mathrm{e}}\right)$ in the second-year cooling of the 2010-12 La Niña event. Climate Dyn., 48, 597-617, https://doi.org/10.1007/s00382-016-3097-4.

Gill, A. E., 1980: Some simple solutions for heat-induced tropical circulation. Quart. J. Roy. Meteor. Soc., 106, 447-462, https:// doi.org/10.1002/qj.49710644905.

Guan, C., and M. J. McPhaden, 2016: Ocean processes affecting the twenty-first-century shift in ENSO SST variability. J. Climate, 29, 6861-6879, https://doi.org/10.1175/JCLI-D-15-0870.1.

Harrison, D. E., and B. S. Giese, 1991: Episodes of surface westerly winds as observed from islands in the western tropical Pacific. J. Geophys. Res., 96 (Suppl.), 3221-3237, https://doi.org/ 10.1029/90JC01775

_- and G. A. Vecchi, 1997: Westerly wind events in the tropical Pacific, 1986-95. J. Climate, 10, 3131-3156, https://doi.org/ 10.1175/1520-0442(1997)010<3131:WWEITT>2.0.CO;2.

Hartten, L., 1996: Synoptic settings of westerly wind bursts. J. Geophys. Res., 101, $16997-17$ 019, https://doi.org/10.1029/ 96JD00030.

Hayashi, M., and M. Watanabe, 2019: Importance of background seasonality over the eastern equatorial Pacific in a coupled atmosphere-ocean response to westerly wind events. Climate Dyn., 52, 7309-7327, https://doi.org/10.1007/S00382-016-3481-0.

Horii, T., I. Ueki, and K. Hanawa, 2012: Breakdown of ENSO predictors in the 2000s: Decadal changes of recharge/ discharge-SST phase relation and atmospheric intraseasonal forcing. Geophys. Res. Lett., 39, L10707, https://doi.org/ 10.1029/2012GL051740.

Hsu, J.-Y., R.-C. Lien, E. D'Asaro, and T. B. Sanford, 2017: Estimates of surface wind stress and drag coefficients in Typhoon Megi 2010. J. Phys. Oceanogr., 47, 545-565, https://doi.org/ 10.1175/JPO-D-16-0069.1.

$\mathrm{Hu}, \mathrm{S}$., and A. V. Fedorov, 2016: Exceptionally strong easterly wind burst stalling El Niño of 2014. Proc. Natl. Acad. Sci. USA, 113, 2005-2010, https://doi.org/10.1073/pnas.1514182113.

Jin, F.-F., 1997: An equatorial ocean recharge paradigm for ENSO. Part I: Conceptual model. J. Atmos. Sci., 54, 811-829, https:// doi.org/10.1175/1520-0469(1997)054<0811:AEORPF>2.0.CO;2.

—, S.-I. An, A. Timmermann, and J. Zhao, 2003: Strong El Niño events and nonlinear dynamical heating. Geophys. Res. Lett., 30, 1120, https://doi.org/10.1029/2002GL016356.

_ , S. T. Kim, and L. Bejarano, 2006: A coupled-stability index for ENSO. Geophys. Res. Lett., 33, L23708, https://doi.org/ 10.1029/2006GL027221.

Keen, R. A., 1982: The role of cross-equatorial tropical cyclone pairs in the Southern Oscillation. Mon. Wea. Rev., 110, 1405-1416, https://doi.org/10.1175/1520-0493(1982)110<1405: TROCET $>2.0 . \mathrm{CO} ; 2$

Kim, H.-M., M.-I. Lee, P. J. Webster, D. Kim, and J. H. Yoo, 2013: A physical basis for the probabilistic prediction of the accumulated tropical cyclone kinetic energy in the western North Pacific. J. Climate, 26, 7981-7991, https://doi.org/10.1175/ JCLI-D-12-00679.1.

Kim, H.-S., C.-H. Ho, J.-H. Kim, and P.-S. Chu, 2012: Trackpattern based model for seasonal prediction of tropical cyclone activity in the western North Pacific. J. Climate, 25, 4660-4678, https://doi.org/10.1175/JCLI-D-11-00236.1.

Knaff, J. A., S. P. Longmore, and D. A. Molenar, 2014: An objective satellite-based tropical cyclone size climatology. J. Climate, 27, 455-476, https://doi.org/10.1175/JCLI-D-1300096.1

Knapp, K. R., D. H. Levinson, H. J. Diamond, and C. J. Neumann, 2010: The International Best Track Archive for Climate Stewardship (IBTrACS): Unifying tropical cyclone data. Bull. Amer. Meteor. Soc., 91, 363-376, https://doi.org/10.1175/ 2009BAMS2755.1.

Korty, R. L., K. A. Emanuel, and J. R. Scott, 2008: Tropical cyclone-induced upper-ocean mixing and climate: Application to equable climates. J. Climate, 21, 638-654, https:// doi.org/10.1175/2007JCLI1659.1.

Kug, J.-S., F.-F. Jin, and S.-I. An, 2009: Two types of El Niño events: Cold tongue El Niño and warm pool El Niño. J. Climate, 22, 1499-1515, https://doi.org/10.1175/2008JCLI2624.1.

Lander, M. A., 1994: An exploratory analysis of the relationship between tropical storm formation in the western North Pacific and ENSO. Mon. Wea. Rev., 122, 636-651, https://doi.org/ 10.1175/1520-0493(1994)122<0636:AEAOTR > 2.0.CO;2.

Lengaigne, M., J.-P. Boulanger, C. Menkes, P. Delecluse, and J. Slingo, 2004: Westerly wind events in the tropical Pacific and their influence on the coupled ocean-atmosphere system: A review. Earth Climate: The Ocean-Atmosphere Interaction, Geophys. Monogr., Vol. 147, Amer. Geophys. Union, 49-69.

Levine, A. F. Z., F.-F. Jin, and M. J. McPhaden, 2016: Extreme noise-extreme El Niño: How state-dependent noise forcing creates El Niño-La Niña asymmetry. J. Climate, 29, 54835499, https://doi.org/10.1175/JCLI-D-16-0091.1.

Li, X., S. Yang, H. Wang, X. Jia, and A. Kumar, 2013: A dynamicalstatistical forecast model for the annual frequency of western Pacific tropical cyclones based on the NCEP Climate Forecast System version 2. J. Geophys. Res., 118, 12 061-12 074, https:// doi.org/10.1002/2013JD020708.

Lian, T., D. Chen, Y. Tang, and Q. Wu, 2014: Effects of westerly wind bursts on El Niño: A new perspective. Geophys. Res. Lett., 41, 3522-3527, https://doi.org/10.1002/2014GL059989.

,-- , and -2017 : The genesis of the 2014-2016 El Niño events. Sci. China Earth Sci., 60, 1589-1600, https://doi.org/ 10.1007/S11430-016-8315-5.

,,,--- X. Liu, J. Feng, and L. Zhou, 2018: Linkage between westerly wind bursts and tropical cyclones. Geophys. Res. Lett., 45, 11 431-11 438, https://doi.org/10.1029/2018GL079745.

McPhaden, M. J., 1999: Genesis and evolution of the 1997-98 El Niño. Science, 283, 950-954, https://doi.org/10.1126/science. 283.5404.950

Meinen, C. S., and M. J. McPhaden, 2000: Observations of warm water volume changes in the equatorial Pacific and their relationship to El Niño and La Niña. J. Climate, 13, 3551-3559, https://doi.org/ 10.1175/1520-0442(2000)013<3551:OOWWVC > 2.0.CO;2.

Menkes, C. E., M. Lengaigne, J. Vialard, M. Puy, P. Marchesiello, S. Cravatte, and G. Cambon, 2014: About the role of westerly wind events in the possible development of an El Niño in 2014. Geophys. Res. Lett., 41, 6476-6483, https://doi.org/10.1002/ 2014 GL061186.

Neske, S., and S. McGregor, 2018: Understanding the warm water volume precursor of ENSO events and its interdecadal variation. Geophys. Res. Lett., 45, 1577-1585, https://doi.org/ 10.1002/2017GL076439.

Philander, S. G., 1981: The response of equatorial oceans to a relaxation of the trade winds. J. Phys. Oceanogr., 11, 
176-189, https://doi.org/10.1175/1520-0485(1981)011<0176: TROEOT $>2.0 . \mathrm{CO} ; 2$.

_- 1990: El Niño, La Niña, and the Southern Oscillation. Academic Press, 293 pp.

Planton, Y., J. Vialard, E. Guilyardi, M. Lengaigne, and T. Izumo, 2018: Western Pacific oceanic heat content: A better predictor of La Niña than of El Niño. Geophys. Res. Lett., 45, 9824-9833, https://doi.org/10.1029/2018GL079341.

Ren, H.-L., and F.-F. Jin, 2013: Recharge oscillator mechanisms in two types of ENSO. J. Climate, 26, 6506-6523, https://doi.org/ 10.1175/JCLI-D-12-00601.1.

Santoso, A., M. McPhaden, and W. Cai, 2017: The defining characteristics of ENSO extremes and the strong 2015/2016 El Niño. Rev. Geophys., 55, 1079-1129, https://doi.org/10.1002/ 2017RG000560.

Smith, T. M., R. W. Reynolds, T. C. Peterson, and J. Lawrimore, 2008: Improvements to NOAA's historical merged landocean temperature analysis (1880-2006). J. Climate, 21, 22832296, https://doi.org/10.1175/2007JCLI2100.1.

Sobel, A. H., and S. J. Camargo, 2005: Influence of western North Pacific tropical cyclones on their environment. J. Atmos. Sci., 62, 3396-3407, https://doi.org/10.1175/JAS3539.1.

,-- A. G. Barnston, and M. K. Tippett, 2016: Northern Hemisphere tropical cyclones during the quasi-El Niño of late 2014. Nat. Hazards, 83, 1717-1729, https://doi.org/10.1007/ S11069-016-2389-7.

Tang, Y., D. Chen, D. Yang, and T. Lian, 2014: Methods of estimating uncertainty of climate prediction and climate change projection. Climate Change: Realities, Impacts Over Ice Cap, Sea Level and Risks, B. R. Singh, Ed., Intech, 397420.

Vecchi, G. A., and D. E. Harrison, 2000: Tropical Pacific sea surface temperature anomalies, El Niño, and equatorial westerly wind events. J. Climate, 13, 1814-1830, https://doi.org/10.1175/ 1520-0442(2000)013<1814:TPSSTA > 2.0.CO;2.
- M. Zhao, H. Wang, G. Villarini, A. Rosati, A. Kumar, I. M. Held, and R. Gudgel, 2011: Statistical-dynamical predictions of seasonal North Atlantic hurricane activity. Mon. Wea. Rev., 139, 1070-1082, https://doi.org/10.1175/2010MWR3499.1.

Wang, B., and J. C. L. Chan, 2002: How strong ENSO events affect tropical storm activity over the western North Pacific. J. Climate, 15, 1643-1658, https://doi.org/10.1175/15200442(2002)015<1643:HSEEAT>2.0.CO;2.

Wang, H., J.-K. Schemm, A. Kumar, W. Wang, L. Long, M. Chelliah, G. D. Bell, and P. Peng, 2009: A statistical forecast model for Atlantic seasonal hurricane activity based on the NCEP dynamical seasonal forecast. J. Climate, 22, 44814500, https://doi.org/10.1175/2009JCLI2753.1.

Wittenberg, A. T., 2009: Are historical records sufficient to constrain ENSO simulations? Geophys. Res. Lett., 36, L12702, https://doi.org/10.1029/2009GL038710.

Wu, Y., L. Chen, C. Hong, T. Li, C. Chen, and L. Wang, 2018: Role of the meridional dipole of SSTA and associated crossequatorial flow in the tropical eastern Pacific in terminating the 2014 El Niño development. Climate Dyn., 50, 1625-1638, https://doi.org/10.1007/s00382-017-3710-1.

Zebiak, S. E., and M.A. Cane, 1987: A model El Niño-Southern Oscillation. Mon. Wea. Rev., 115, 2262-2278, https://doi.org/ 10.1175/1520-0493(1987)115<2262:AMENO>2.0.CO;2.

Zhang, H., and Coauthors, 2018: Net modulation of upper ocean thermal structure by Typhoon Kalmaegi (2014). J. Geophys. Res. Oceans, 123, 7154-7171, https://doi.org/10.1029/2018JC014119.

Zhang, R.-H., and C. Gao, 2016: The IOCAS intermediate coupled model (IOCAS ICM) and its real-time predictions of the 2015-2016 El Niño event. Sci. Bull., 61, 1061-1070, https:// doi.org/10.1007/s11434-016-1064-4.

, and —, 2017: Processes involved in the second-year warming of the 2014-15 El Niño event as derived from an intermediate ocean model. Sci. China Earth Sci., 60, 1601-1613, https://doi.org/10.1007/s11430-016-0201-9. 